\title{
International Monetary Trade and the Law of One Price ${ }^{1}$
}

\author{
Gabriele Camera \\ Johannes Winkler \\ Purdue University Dresdner-Kleinwort-Wasserstein
}

20 August, 2002

\begin{abstract}
We endogenize circulation of currencies and price formation in a decentralized monetary trading environment with two countries and two currencies. In equilibrium sellers of homogenous goods may post prices in the national or also in the foreign currency, given unobservable buyers' valuations. We prove that, under different monetary regimes, the absence of well integrated international goods markets doesn't necessarily imply a violation of the law of one price. We also illustrate the behavior of prices across regimes characterized by different degrees of monetary integration.
\end{abstract}

Keywords: search, international currency, price posting, money.

\footnotetext{
${ }^{1}$ Corresponding author: Gabriele Camera, 1310 Krannert, Purdue University, West Lafayette, IN 47907-1310, Gcamera@mgmt.purdue.edu. We thank Gaetano Antinolfi and Massimo Guidolin for comments. An earlier version of this paper titled "Currency Substitution and the Law of One Price" has been presented in seminars at Indiana U., ITAM, Purdue, U. of Kentucky, the Econometric Society World Congress 2000 (Seattle), the year 2000 meetings of the SED (San Jose', Costa Rica), and the Midwest Macro (U. of Iowa). G. Camera acknowledges financial support from Purdue's Center for International Business and Economics Research and the Purdue Research Foundation. J. Winkler contributed to this research while a graduate student at Purdue. Paola Boel provided research assistance.
} 


\section{Introduction}

An old economic tenet maintains that, absent restrictions on goods arbitrage, the equilibrium prices of a good sold on perfectly competitive foreign and domestic markets should be identical once converted to a common currency. Empirical evidence challenges models of international trade based on this equilibrium view, by pointing to the general failure of the law of one price at most disaggregated product levels, with few exceptions (see the survey of Rogoff, 1996). A common explanation is that international goods markets are not nearly as integrated as domestic markets. Trading frictions, such as transportation or information costs, may act as impediments for international commodity arbitrage, affecting the international flow of goods and relative prices.

We develop a theoretical study of decentralized monetary exchange in a two-country setting where trading difficulties are made explicit, and currencies' values are endogenously determined. Our goal is to examine the theoretical implications of the absence of well integrated international goods markets on domestic and foreign prices of homogeneous traded goods. We ask if international trading frictions are sufficient to account for the startling empirical failure of the law of one price. We provide a negative answer, by means of rigorous theoretical examples. To do so we study the pricing behavior of domestic and foreign sellers, and endogenize the currencies' circulation patterns. When is it advantageous to post prices in a foreign as well as a domestic money? How would their purchasing powers compare? Would prices be lower?

Our analysis is developed within the framework of a recent theoretical literature in which money has an explicit role as a medium of exchange. We build a general equilibrium decentralized international trading environment where the absence of well integrated markets is modeled by representing trade as a random search process. As a result, inconvertible and intrinsically worthless monies have value in equilibrium if they can facilitate the spot exchange of goods whose consumption generates utility. ${ }^{2}$

Several reasons suggest this modeling avenue. First, it is a natural way to make explicit the link between exchange frictions and relative prices, but also trade flows (as noted by Rauch, 1999). Second, the use of a theoretical framework where trade is multilateral and centralized would not give satisfactory account of the relation between the monetary system in use and the price mechanism

\footnotetext{
${ }^{2}$ Matsuyama et al. (1993) first proposed a two-countries two-monies model of this type, with fixed prices. Of the extensions published, a recent one incorporates flexible prices (Wright and Trejos, 2001).
} 
(Hellwig, 1993). Third, we want to study equilibrium use of a currency as the result of decentralized and uncoordinated private decisions, and not of government action.

To make the theoretical implications transparent, we consider a setting that abstracts from sophisticated financial markets or trade intermediaries. There are two countries with immobile factors of production, distinct currencies, and heterogeneous trading environments. Due to specialization in production and tastes, agents must trade locally or internationally to consume. This process is subject to spatial and informational frictions, with international trade more difficult than local. Buyers are randomly paired to sellers, and maximize expected utility by choosing when to spend their money. Sellers maximize profits by choosing the money they accept and the prices to post in their store, given that buyers' preferences and nationality are unobservable. The countries' heterogeneity and the trade frictions may induce price disparity across economies.

Our main contribution is to prove that the absence of well integrated international goods markets does not per se imply a violation of the law of one price. In fact, despite the presence of international trade frictions, equilibria exist where local stores accept a foreign currency and prices in that money are identical across countries. We show that this result holds under different monetary regimes in which the two monies may or may not compete as international media of exchange. Our analysis also suggests that the use of a foreign money for internal trade (often referred to as 'currency substitution') is associated with scarcity of liquidity. When a foreign currency complements the domestic money as means of payment, this tends to improve the functioning of the domestic economy by supporting more efficient spot exchange. While this may benefit the domestic economy, by lowering prices, it may hurt the foreign economy if it experiences a liquidity drain, as a result.

This study makes a further contribution. By adopting a seller-posting-price protocol, we extend prior work on existence of monetary equilibria in divisible-goods versions of the search-theoretic model of Kiyotaki and Wright (1989), when price formation is endogenous. ${ }^{3}$ We prove that symmetric monetary equilibria in pure strategies exist only if the money stock is neither excessive nor too limited (i.e. sales opportunities are neither infrequent, nor plentiful), and agents are sufficiently patient. Otherwise, sellers would post the highest reservation price, depriving money of value.

\footnotetext{
${ }^{3}$ After completing an initial draft of this paper, we learned of a study independently written by Curtis-Soller and Wright (2000), that focuses on monetary equilibria with posted prices in a one-country one-currency model.
} 


\section{Environment}

The model is a divisible-goods version of Kiyotaki and Wright (1989). Time is continuous and goes on forever. There is a continuum of individuals and goods, normalized to one, belonging to one of two countries identified by $d \in\{D, F\}$. A fraction $P<1$ of individuals belongs to the domestic economy, $D$, and $1-P$ live in the foreign economy, $F$. In each country there are $N \geq 3$ types of agents and $N$ types of goods, each in proportion $\frac{1}{N}$. Let $i \in \mathbf{N} \equiv\{1, . ., N\}$ denote an individual type, and let $n \in \mathbf{N}$ denote a good type.

Individuals derive different utility from different good types, having homogeneous cardinal preferences, but heterogeneous ordinal preferences over goods types. Preferences for good $n=i+i^{\prime}$ of an agent of type $i$ are monotonically decreasing in $i^{\prime} \in\{0, . ., N-1\}$, where $n$ is modulo $N$. Thus, the distribution over the rank ordering of good types is uniform and symmetric across countries and individual types, and a proportion $1 / N$ of agents likes any good $i$ the most in each country. ${ }^{4}$

We let the temporary utility of agent $i$ from consumption of $q$ units of good $n$ take the form $u_{i}\left(q_{n}\right)=\left(q a_{i, n}\right)^{\gamma}$ with $\gamma \in(0,1), a_{i, n}=a_{i+1, n+1} \forall i, n(\bmod . N)$, and $1=a_{i, i}>a_{i, i+1}>\ldots a_{i, N}>$ $\ldots a_{i, i-1}=0 \forall i(\bmod . N)$. Hence, agent $i$ has greater valuation for good $n$ than agent $j$ if $a_{i, n}>a_{j, n}$, and own production does not provide utility. The future is discounted at rate $r>0$.

A fraction $M \in(0,1)$ of the population is initially randomly endowed with one unit of indivisible fiat money, domestic or foreign. We denote the initial supply of domestic (resp. foreign) currency by $M_{D}\left(\right.$ resp. $\left.M_{F}\right)$, thus

$$
M_{D}+M_{F}=M
$$

The $1-M$ fraction of individuals who start life without money is endowed with a production opportunity. This allows an agent of type $i$ to produce $q \geq 0$ units of a perishable and homogeneous good of type $i-1(\bmod$. $N)$ suffering disutility $c(q)=q$. A new production opportunity freely arises following consumption. Thus, we call 'buyers' the agents with money, and 'sellers' the others.

For simplicity we assume that buyers search for sellers who are located at fixed points, and are paired randomly at each date according to the following Poisson process. Domestic agents meet each other at rate $\alpha_{D}=P k$, and meet a foreign agent at rate $\alpha_{F}=(1-P) k^{\prime}$. Foreign agents meet

\footnotetext{
${ }^{4}$ If we imagine good types as being distributed along a circle, an agent of type $i$ likes good $i$ the most, likes progressively less the goods encountered moving clockwise, and likes the least good $i-1$ (modulo $N$ ). An extreme case is Kiyotaki and Wright (1989), where $N=3$, and agent $i$ likes only good $n=i$.
} 
each other at rate $\alpha_{F}^{\prime}=(1-P) k$, and meet a domestic agent at rate $\alpha_{D}^{\prime}=P k^{\prime}$. The parameter $k^{\prime}>0$ denotes the degree of economic integration between countries, while $k>0$ determines the matching rate within a country. ${ }^{5}$ This specification implies that the total number of meetings that the domestic population has with foreigners, $P \alpha_{F}$, is identical to the total number of meetings that the foreign population has with domestic agents, $(1-P) \alpha_{D}^{\prime}$.

Consider a match. It is assumed that money and output type are observable, but not preferences and nationality. Trade histories are private information, agents cannot commit to future actions, and transfers cannot be enforced. The trading mechanism is as follows. If a seller chooses to trade, he gets to 'post' the price, i.e. he makes an offer that the buyer can only accept or reject. If disagreement results, no trade takes place. Posting a price is costly for the seller, as he suffers small disutility from doing so. This is small, however, in that we consider the limiting case where this disutility goes to zero.

The assumptions made keep the model tractable without sacrificing the rigorousness of the analysis. Specifically, preference and technologies motivate the existence of specialization in production and consumption, and of gains from trade. The information, commitment, and enforcement limitations rule out intertemporal trade and imply that spot trade must be facilitated by media of exchange. The assumed matching process allows us to focus solely on trades of goods for money. This, together with the assumed production technology and money indivisibility, allows us to avoid tracking complex distributions of nominal balances (e.g. Green and Zhou, 1998, or Camera and Corbae, 1999). Finally, the trading mechanism adopted is motivated by the ordinary observation that in retail transactions stores post prices.

\section{Symmetric Stationary Equilibria with Homogeneous Prices}

We focus on stationary and symmetric Nash monetary equilibria, where distributions are stationary and agents who are in an identical state adopt identical, time-invariant strategies. In equilibrium, actions are individually optimal, and based on the correct evaluation of exchange opportunities and gains from trade.

Consider a representative domestic agent of type $i$ (foreigners are not discussed, if the implica-

\footnotetext{
${ }^{5}$ Much as in Matsuyama et al. (1993), these parameters control national/international trade frictions. We can choose $P, k$, and $k^{\prime}$ so that, for instance, $\alpha_{D}>\alpha_{F}$ and $\alpha_{F}^{\prime}>\alpha_{D}^{\prime}$, i.e. international trade is more difficult than local, in both economies, or $\alpha_{F} \neq \alpha_{D}^{\prime}$, i.e. international matching rates differ across countries.
} 
tions are understood). At each date, he can be a buyer or a seller who selects actions to maximize her expected lifetime utility, taking as given strategies of others, trade opportunities, and market prices.

As a seller, the agent's strategy encompasses two choices: whether to pursue a trade for a given currency and, contingent on that, the price(s) to be posted. For ease of exposition we break her problem in two parts, moving backward. Contingent on selling for currency $d$, let $Q_{d, i-1} \geq 0$ denote the seller's stationary quantity offer of good $i-1$, so that $Q_{d, i-1}^{-1}$ is the nominal price in money $d$. Define $Q=\left\{Q_{d, i}\right\}_{\forall d, i}\left(Q^{\prime}\right.$ if a foreign seller), and let $q$ and $q^{\prime}$ be the equilibrium market offers. Given $Q_{s, i-1}$, let $\Pi_{d}$ be the stationary probability that a domestic seller, of any type $i$, chooses to trade with someone who has currency $d$, in a symmetric equilibrium. Note that $\Pi_{d}$ is independent of seller's type (due to symmetry) and buyer's nationality (which is private information). Define $\Pi=\left\{\Pi_{D}, \Pi_{F}\right\}$, and let $\pi$ and $\pi^{\prime}$ denote the equilibrium strategies of all others.

As a buyer with currency $d$, domestic agent $i$ must choose when to spend her money. Contingent on a random trade match with domestic (resp. foreign) seller $h+1 \in \mathbf{N}$, he chooses the probability $B_{d, i}\left(q_{d, h}\right)$ to buy at the posted price $q_{d, h}^{-1}$ (resp. $\left.B_{d, i}\left(q_{d, h}^{\prime}\right)\right)$. Define $B=\left\{B_{d, i}\left(q_{d, h}\right), B_{d, i}\left(q_{d, h}^{\prime}\right)\right\}_{\forall i, h, d}$ ( $B^{\prime}$ if foreign) and let $\beta$ and $\beta^{\prime}$ denote the equilibrium strategies of all others. Finally, let $\mathbf{q}=\left\{q, q^{\prime}\right\}$, $\mathbf{Q}=\left\{Q, Q^{\prime}\right\}, \boldsymbol{\Pi}=\left\{\Pi, \Pi^{\prime}\right\}, \boldsymbol{\pi}=\left\{\pi, \pi^{\prime}\right\}, \mathbf{B}=\left\{B, B^{\prime}\right\}$, and $\boldsymbol{\beta}=\left\{\beta, \beta^{\prime}\right\}$.

It should be obvious that sellers accepting the same money could price goods unequally. Thus, several international and local price distributions can be conjectured. As our focus is equilibria with the law of one price, in what follows we restrict attention to outcomes where same-currency prices are homogeneous within a country. We call them equilibria with 'locally homogenous prices.'

\subsection{Distribution of money}

In a symmetric equilibrium money must be identically distributed across types. We let $m_{d}$ denote the proportion of domestic buyers with currency $d$, for any $i$ ( $m_{d}^{\prime}$ if foreign). Hence

$$
m=m_{D}+m_{F} \quad \text { and } \quad m^{\prime}=m_{D}^{\prime}+m_{F}^{\prime}
$$

are the proportion of buyers, of any type, in the domestic and foreign economy, respectively. In a monetary equilibrium, all money must be held:

$$
P m_{d}+(1-P) m_{d}^{\prime}=M_{d} \quad \forall d \in\{D, F\} .
$$


It follows that a proportion $1-m$ of domestic agents of every type $i$ are sellers, and $m$ are buyers $\left(1-m^{\prime}\right.$ and $m^{\prime}$ if foreign). Denote by $\mathbf{m}=\left\{m_{d}, m_{d}^{\prime}\right\}_{\forall d}$ the stationary distribution of currency.

We discuss the laws of motion by considering the domestic economy. Note that $m_{d}$ is stationary when the inflow of domestic agents who have sold goods for money $d$, is equal to the outflow of domestic agents who have spent money $d$ locally or abroad. Hence, in a symmetric equilibrium the law of motion for domestic and foreign buyers with money $d$ must satisfy:

$$
\begin{aligned}
& \dot{m}_{d}=P(1-m) \alpha_{F} m_{d}^{\prime} \pi_{d} \frac{\sum_{h \in \mathbf{N}} \beta_{d, h}^{\prime}\left(q_{d, i-1}\right)}{N}-P m_{d} \alpha_{F}\left(1-m^{\prime}\right) \pi_{d}^{\prime} \frac{\sum_{h \in \mathbf{N}} \beta_{d, i}\left(q_{d, h}^{\prime}\right)}{N} \\
& \dot{m}_{d}^{\prime}=(1-P)\left(1-m^{\prime}\right) \alpha_{D}^{\prime} m_{d} \pi_{d}^{\prime} \frac{\sum_{h \in \mathbf{N}} \beta_{d, h}\left(q_{d, i-1}^{\prime}\right)}{N}-(1-P) m_{d}^{\prime} \alpha_{D}^{\prime}(1-m) \pi_{d} \frac{\sum_{h \in \mathbf{N}} \beta_{d, i}^{\prime}\left(q_{d, h}\right)}{N} .
\end{aligned}
$$

Consider the first line. Only international exchanges appear, since internal trade does not affect $m_{d}$ (domestic buyers and sellers just swap asset positions). A proportion $1-m$ of domestic sellers (of each type $i$ ) meets foreign buyers with money $d$, at rate $\alpha_{F} m_{d}^{\prime}$. The sellers trade with probability $\pi_{d}$, posting the price $q_{d, i-1}^{-1}$, and buyers of type $h$ buy with probability $\beta_{d, h}^{\prime}\left(q_{d, i-1}\right)$. Hence, $m_{d}$ rises at rate $(1-m) \alpha_{F} m_{d}^{\prime} \pi_{d} \frac{\sum_{h \in \mathbf{N}} \beta_{d, h}^{\prime}\left(q_{d, i-1}\right)}{N} .6$ When domestic buyers, who have money $d$, make a purchase abroad, $m_{d}$ decreases. These buyers meet foreigners who sell for money $d$, at rate $\alpha_{F}\left(1-m^{\prime}\right) \pi_{d}^{\prime}$. Trade with a seller $h+1$ occurs with probability $\beta_{d, i}\left(q_{d, h}^{\prime}\right)$, given her offer $q_{d, h}^{\prime}$. Thus $m_{d}$ falls at rate $m_{d} \alpha_{F}\left(1-m^{\prime}\right) \pi_{d}^{\prime} \frac{\sum_{h \in \mathbf{N}} \beta_{d, i}\left(q_{d, h}^{\prime}\right)}{N}$. Similar considerations can be made for $m_{d}^{\prime}$.

\subsection{Value Functions}

Consider a domestic agent of type $i$. Taking as given $\{\boldsymbol{\pi}, \boldsymbol{\beta}, \mathbf{q}, \mathbf{m}\}$ he selects actions that maximize her utility from consumption. Let $V_{s, i}$ and $V_{d, i}$ denote the expected stationary lifetime utility of a seller and buyer with currency $d$, respectively. Let a prime refer to foreign agents, and let $\mathbf{V}=\left\{V_{s, i}, V_{s, i}^{\prime}, V_{d, i}, V_{d, i}^{\prime}\right\}_{\forall i, d}$. Given the recursive structure of the model, seller's $i$ value function must satisfy:

$$
\begin{aligned}
& \rho V_{s, i}=\sum_{\forall d} \max _{\Pi_{d}, Q_{d, i-1}} \Pi_{d} \Omega\left(Q_{d, i-1}\right) \\
& \rho V_{s, i}^{\prime}=\sum_{\forall d} \max _{\Pi_{d}^{\prime}, Q_{d, i-1}^{\prime}} \Pi_{d}^{\prime} \Omega\left(Q_{d, i-1}^{\prime}\right)
\end{aligned}
$$

\footnotetext{
${ }^{6}$ Notice that $P(1-m) \alpha_{F} m_{d}^{\prime}=(1-P) m_{d}^{\prime} \alpha_{D}^{\prime}(1-m)$, i.e. the rate at which domestic sellers meet foreign buyers is the same at which domestic sellers are met by foreign buyers.
} 
Here $\rho=r N$ is the discount rate normalized by the agents' types (since pairings are random) and

$$
\begin{aligned}
& \Omega\left(Q_{d, i-1}\right) \equiv \sum_{h \in \mathbf{N}}\left[\alpha_{D} m_{d} \beta_{d, h}\left(Q_{d, i-1}\right)+\alpha_{F} m_{d}^{\prime} \beta_{d, h}^{\prime}\left(Q_{d, i-1}\right)\right]\left(V_{d, i}-Q_{d, i-1}-V_{s, i}\right) \\
& \Omega\left(Q_{d, i-1}^{\prime}\right) \equiv \sum_{h \in \mathbf{N}}\left[\alpha_{D}^{\prime} m_{d} \beta_{d, h}\left(Q_{d, i-1}^{\prime}\right)+\alpha_{F}^{\prime} m_{d}^{\prime} \beta_{d, h}^{\prime}\left(Q_{d, i-1}^{\prime}\right)\right]\left(V_{d, i}^{\prime}-Q_{d, i-1}^{\prime}-V_{s, i}^{\prime}\right)
\end{aligned}
$$

are the expected flow returns (to domestic and foreign sellers, respectively) earned from trading output for currency $d$.

The expressions in (5) are standard Bellman equations. The first line, for instance, indicates that at each date a domestic seller maximizes her return from trade by choosing $\left\{\Pi_{d}, Q_{d, i-1}\right\}$, i.e. whether to trade with a buyer who has currency $d$ and what price to post. These actions cannot be based on the buyer's types or nationality (unobserved), hence the seller's surplus from trade is independent of $h$. It is $V_{d, i}-V_{s, i}$, a capital gain in a monetary equilibrium, minus the production cost $Q_{d, i-1}$. The seller's period return, however, does not depend only on the price posted, but also on the likelihood of a sale. This is affected by $\alpha_{d}$ (i.e. the trade frictions), and the buyers' strategies. For example, if the seller posts $Q_{d, i-1}^{-1}$, trade with some domestic buyer is expected to occur at rate $\sum_{h \in \mathbf{N}} \alpha_{D} m_{d} \beta_{d, h}\left(Q_{d, i-1}\right)$, normalized by $N$.

Under the conjecture that prices in denomination $d$ are locally homogeneous, their distribution has a single mass point in each country. Hence, the flow return from trade of a domestic and foreign buyer of type $i$ and with money $d$ are, respectively:

$$
\begin{aligned}
\rho V_{d, i}= & \alpha_{D}(1-m) \pi_{d} \sum_{h \in \mathbf{N}} \max _{B_{d, i}\left(q_{d, h}\right)} B_{d, i}\left(q_{d, h}\right)\left[V_{s, i}+u_{i}\left(q_{d, h}\right)-V_{d, i}\right] \\
& +\alpha_{F}\left(1-m^{\prime}\right) \pi_{d}^{\prime} \sum_{h \in \mathbf{N}} \max _{B_{d, i}\left(q_{d, h}^{\prime}\right)} B_{d, i}\left(q_{d, h}^{\prime}\right)\left[V_{s, i}+u_{i}\left(q_{d, h}^{\prime}\right)-V_{d, i}\right] \\
\rho V_{d, i}^{\prime}= & \alpha_{D}^{\prime}(1-m) \pi_{d} \sum_{h \in \mathbf{N}} \max _{B_{d, i}^{\prime}\left(q_{d, h}\right)} B_{d, i}^{\prime}\left(q_{d, h}\right)\left[V_{s, i}^{\prime}+u_{i}\left(q_{d, h}\right)-V_{d, i}^{\prime}\right] \\
& +\alpha_{F}^{\prime}\left(1-m^{\prime}\right) \pi_{d}^{\prime} \sum_{h \in \mathbf{N}} \max _{B_{d, i}^{\prime}\left(q_{d, h}^{\prime}\right)} B_{d, i}^{\prime}\left(q_{d, h}^{\prime}\right)\left[V_{s, i}^{\prime}+u_{i}\left(q_{d, h}^{\prime}\right)-V_{d, i}^{\prime}\right]
\end{aligned}
$$

The first two lines of (7) indicate that a domestic buyer may meet domestic or foreign sellers. For example, possibilities to trade domestically at price $q_{d, h}^{-1}$ arrive at rate $\alpha_{D}(1-m) \pi_{d}$, and the buyer spends her money with probability $B_{d, i}\left(q_{d, h}\right)$. Her surplus is $V_{s, i}+u_{i}\left(q_{d, h}\right)-V_{d, i}$, i.e. the period utility $u_{i}\left(q_{d, h}\right)$ plus the net continuation payoff $V_{s, i}-V_{d, i}$, a capital loss in a monetary equilibrium.

Notice that $V_{s, i}$ and $V_{d, i}$ are bounded below (by zero) and above (the match's surplus, $u(q)-q$, is bounded and $r>0$ ). As agents of identical nationalities face identical trading environments, it 
should be obvious that in a symmetric equilibrium:

$$
V_{s, i}=V_{s}, \quad V_{d, i}=V_{d}, \quad V_{s, i}^{\prime}=V_{s}^{\prime}, \quad V_{d, i}^{\prime}=V_{d}^{\prime}, \quad \forall i, d
$$

Although the capital gains $V_{d}-V_{s}$ are type-independent, they are not nationality-independent, as trading environments may vary across borders. This means that identical buyers of different nationalities will generally attach different values to the same purchase, hence their reservation prices will generally differ.

The key implication is that the heterogeneity in countries' trading environments generates price disparities across countries. However, agents cannot easily arbitrage these disparities away due to the presence of international trade frictions. Hence, the model can give rise to several stationary equilibria with departures from the law of one price, as the following section makes clear.

\subsection{Equilibrium Strategies and Prices}

In choosing her optimal strategy as a buyer or a seller, the representative domestic agent of type $i$ takes as given the offers present in the market, $\mathbf{q}$, the strategies of all others, $\{\boldsymbol{\pi}, \boldsymbol{\beta}\}$, and the distribution of money, $\mathbf{m}$.

Consider the optimal strategy of this agent, as a buyer with money $d$. In a random trade match he buys good $h$ at price $q_{d, h}^{-1}$ if her surplus is non-negative, i.e.:

$$
B_{d, i}\left(q_{d, h}\right)\left\{\begin{array}{l}
=1 \text { if } V_{s, i}+u_{i}\left(q_{d, h}\right) \geq V_{d, i} \\
=0 \text { otherwise. }
\end{array}\right.
$$

Notice that consideration of pure strategies, in matches where there are gains from trade, is without loss in generality because prices are fully flexible. A seller would prefer to marginally lower the price to induce a purchase by an indifferent buyer type, rather than having the buyer mix. Thus, $B_{d, i}\left(q_{d, h}\right) \in\{0,1\}$ is the only sub-game perfect equilibrium strategy.

Now consider a representative domestic seller of type $i$. Suppose only pure strategies $\Pi$ are adopted (we argue that this is without loss in generality, below). Contingent on trading with a buyer who has money $d$, i.e. given $\Pi_{d}=1$, the seller chooses $Q_{d, i-1}$ to maximize the expected flow return $\Omega\left(Q_{d, i-1}\right)$. He cannot extract the entire surplus of every buyer randomly met, as the buyer's valuation is unobservable. Thus, the seller faces a trade-off. He can charge a higher price to increase her surplus share, at the expense of every buyer's. This, however, may decrease the 
probability of a sale because of buyers' heterogeneity. A high price may leave negative surplus to buyers of some type and nationality, inducing them to avoid the purchase.

What offers are optimal, then? Since buyers accept offers leaving them zero surplus, sellers worry only about buyer's reservation prices. That is, the symmetric equilibrium offers extract all surplus from a buyer type of some nationality, and belong to the set containing all $Q_{d, i-1}>0$ that satisfy either $V_{d}-V_{s}=u_{h}\left(Q_{d, i-1}\right)$ or $V_{d}^{\prime}-V_{s}^{\prime}=u_{h}\left(Q_{d, i-1}\right)$, for $h \neq i .^{7}$ This set, we stress, is rather large. It contains up to $2(N-1)$ distinct elements since (i) there are $N-1$ agent types who like differently the same good type, and (ii) a currency may be valued differently abroad.

As the reservation price set is discrete, the offer that maximizes $\Omega\left(Q_{d, i-1}\right)$ may not be unique. The seller, for instance, could be indifferent between two prices (e.g. see Curtis-Soller and Wright, 2000). Since we focus on equilibria with locally homogeneous prices, however, in equilibrium the optimal price must be unique. That is, given $\Pi_{d}=1$, we say that $Q_{d, i-1}$ is optimal if:

$$
\begin{gathered}
\Omega\left(Q_{d, i-1}\right)>\Omega\left(\tilde{Q}_{d, i-1}\right) \forall \tilde{Q}_{d, i-1} \neq Q_{d, i-1} \\
\text { and } \\
V_{d}-V_{s}=u_{h}\left(Q_{d, i-1}\right) \text { or } V_{d}^{\prime}-V_{s}^{\prime}=u_{h}\left(Q_{d, i-1}\right) \text { for some } h \neq i .
\end{gathered}
$$

Contingent on $Q_{d, i-1}$ being optimally chosen, we discuss $\Pi_{d}$ in a match. Due to (infinitesimal) disutility from posting prices, the seller trades only if he believes money $d$ is accepted somewhere and a mutually gainful trade is possible. Else, he chooses $\Pi_{d}=0$. Technically, in a match a trade for money $d$ occurs only if $\Omega\left(Q_{d, i-1}\right)>0,{ }^{8}$ i.e. the seller's optimal trade strategy must satisfy:

$$
\Pi_{d}=\left\{\begin{array}{l}
1 \text { if } \Omega\left(Q_{d, i-1}\right)>0 \\
0 \text { otherwise }
\end{array}\right.
$$

where $\Pi_{d} \in\{0,1\}$ is without loss of generality, as prices are flexible. ${ }^{9}$ In a monetary equilibrium

$$
V_{d}>V_{s} \text { for some } d \text {. }
$$

\footnotetext{
${ }^{7}$ Suppose the seller posts a price which leaves positive surplus to some buyer, and zero surplus to no-one. He can increase the price a bit, earning a larger surplus from every possible sale, without lowering the probability of a sale.

${ }^{8}$ Suppose money $d$ is accepted abroad but not locally ( $d$ circulates only abroad). Suppose, however, a local seller meets a local buyer with money $d$, and gains from trade exist. Since buyers' nationality is unobservable, the seller attaches zero probability to having met a local agent, and refuses to trade to avoid the transaction cost.

${ }^{9}$ If $\Omega\left(Q_{d, i-1}\right)=0$ and some buyer earns surplus, the seller could advantageously increase the price. If there are no gains from trade, $\Pi_{d}=0$ due to the disutility from entering a trade. Finally, $Q_{d, i-1}=0$ is equivalent to setting $\Pi_{d}=0$, since buyers would not trade.
} 
The individually optimal strategies of foreigners are equivalent (just add a "' where appropriate). In a symmetric equilibrium trade strategies must be type-independent, and so must be prices:

$$
q_{d, i-1}=q_{d} \text { and } q_{d, i-1}^{\prime}=q_{d}^{\prime} \quad \forall i, d .
$$

Finally, aggregate consistency requires:

$$
\{\mathbf{B}, \boldsymbol{\Pi}, \mathbf{Q}\}=\{\boldsymbol{\beta}, \boldsymbol{\pi}, \mathbf{q}\}
$$

Definition. A symmetric stationary monetary equilibrium with locally homogeneous prices is defined to be $\{\mathbf{m}, \boldsymbol{\beta}, \boldsymbol{\pi}, \mathbf{q}, \mathbf{V}\}$ that satisfy (4)-(14), the foreign equivalents of (9)-(12), and $\dot{\mathbf{m}}=0$.

We conclude by noting the implausibility of thinking that local price homogeneity implies worldwide price homogeneity. In fact, (10) makes it clear that the price set is very rich, and that sellers of different nationalities may select dissimilar prices, due to heterogeneous trade opportunities. ${ }^{10}$

\section{A Simple Class of Equilibria}

We have shown that the set of possible outcomes is rather large. First, prices could range from very low, when everyone buys, to very high, when only few buy. Second, as monies are intrinsically useless and inconvertible, several monetary trade patterns are possible (e.g. one money does not circulate at all). Studying all permutations is beyond our purposes, so we take two steps. First, we study equilibria where sales take place whenever gains from trade exist, i.e. sellers post the lowest reservation price. Second, we focus on the most representative monetary regimes: local circulation of currencies and international circulation of one or both currencies.

For tractability, we assume $N=3$ and $a_{i, i+1}=a \in(0,1)$. Let $\bar{q}=a^{\frac{\gamma}{1-\gamma}}$ be the largest traded quantity, i.e. the one at which the trade surplus of a low valuation buyer, $(a q)^{\gamma}-q$, vanishes. We organize the discussion as follows. First, we prove existence of outcomes where the law of one price holds under the different monetary regimes. Then, with the help of numerical experiments, we illustrate the key characteristics of the terms of trade across the different regimes, and welfare. We start by studying the case of local circulation. This builds intuition on the basic properties of

\footnotetext{
${ }^{10}$ For example if $N=3$, there are four reservation prices, in any currency. Two 'low' prices target, respectively, low-valuation local or foreign buyers, while two 'high' prices exist that target, respectively, high-valuation local or foreign buyers. Thus, sixteen price vectors are possible, twelve of which imply international price dispersion.
} 
equilibria where sellers post the lowest reservation price. This intuition will carry over to the less tractable cases with international monetary exchange.

\subsection{Local Currencies}

Conjecture that domestic (resp. foreign) sellers refuse trades in money $F$ (resp. D), but national currencies are accepted, i.e. $\pi_{F}=\pi_{D}^{\prime}=0$ and $\pi_{D}=\pi_{F}^{\prime}=1$. Then, local monies are held solely locally i.e. $m_{F}=m_{D}^{\prime}=0$ and $m=m_{D}=\frac{M_{D}}{P}$ and $m^{\prime}=m_{F}^{\prime}=\frac{M_{F}}{1-P}$, only if $M_{D}<P<1-M_{F}$ (since at most every agent can have a unit of money).

In equilibrium a domestic seller of good $i$ engages only in domestic sales for domestic money. He chooses one of two reservation prices, high or low, targeting domestic buyers. The high price leaves no surplus to high valuation buyers, and satisfies $u_{i}\left(Q_{D, i}\right)=V_{D}-V_{s}$ so that trade does not occur with low-valuation agents. The low price leaves some (resp. no) surplus to high-valuation (resp. low-) buyers and satisfies $u_{i-1}\left(Q_{D, i}\right)=V_{D}-V_{s}$. A sale takes place any time gains from trade exist, i.e. in matches with agents $i-1$ and $i$ with money $D$.

When domestic sellers uniformly post the low reservation price, $q_{D}$ must satisfy

$$
\left(a q_{D}\right)^{\gamma}=V_{D}-V_{s}
$$

In this case $\beta_{D, i}\left(q_{D, h}\right)=1$ for $h \in\{i, i+1\}$, and (5)-(7) greatly simplify:

$$
\begin{aligned}
& \rho V_{s}=2 \alpha_{D} m_{D}\left(V_{D}-q_{D}-V_{s}\right) \\
& \rho V_{D}=\alpha_{D}\left(1-m_{D}\right)\left(V_{s}+q_{D}^{\gamma}-V_{D}\right) .
\end{aligned}
$$

The first line in (16), for instance, tells us that sales occur at rate $2 \alpha_{D} m_{D}$, since two types of buyers desire the good offered, and local sellers trade only for local currency, held only locally. This gives them surplus $V_{D}-q_{D}-V_{s}$. Using (15)-(16) we find unique equilibrium prices:

$$
\begin{gathered}
q_{D}=\left\{\frac{a^{\gamma}\left[\rho+\alpha_{D}(1+m)\right]-\alpha_{D}(1-m)}{2 m \alpha_{D}}\right\}^{\frac{1}{1-\gamma}} \\
q_{F}^{\prime}=\left\{\frac{a^{\gamma}\left[\rho+\alpha_{F}^{\prime}\left(1+m^{\prime}\right)\right]-\alpha_{F}^{\prime}\left(1-m^{\prime}\right)}{2 m^{\prime} \alpha_{F}^{\prime}}\right\}^{\frac{1}{1-\gamma}} .
\end{gathered}
$$

The key to proving that these prices and strategies are indeed an equilibrium, is to verify not only that sellers earn surplus, but also that they have no incentive to deviate either by charging the higher price, or by accepting a competing currency. 
Proposition 1. If $\rho \leq \bar{\rho}, \frac{M_{D}}{P} \in(\underline{m}, \bar{m}), \frac{M_{F}}{1-P} \in\left(\underline{m}^{\prime}, \bar{m}\right), \alpha_{F} \leq \bar{\alpha}_{F}$, and $\alpha_{D}^{\prime} \leq \bar{\alpha}_{D}^{\prime}$, then there exists a unique low-price equilibrium where currencies circulate only locally, and prices are locally homogeneous.

Proof. In Appendix. ${ }^{11}$

The key to local circulation is the presence of large international trade frictions, i.e. $\alpha_{F}$ and $\alpha_{D}^{\prime}$ must be small. This confirms prior results based on a different pricing mechanism (Wright and Trejos, 2001). In equilibrium a foreign money has very little value domestically, if it is not used for internal trade and its use in international trade is sporadic. This motivates domestic agents to refuse offers to sell for foreign money, so that they trade only locally with the national money.

To understand why equilibrium prices are low, instead we must discuss a trade-off existing between ease of trade, governed by amount of money and trade frictions, and return per sale. The conditions on liquidity and discounting guarantee that the representative seller does not prefer to raise her price above the market.

Sellers must be willing to produce more currently, rather than less, in exchange for money that will only finance future purchases. Thus, they must be patient, $\rho \leq \bar{\rho}$. The amount of liquidity affects the sales frequency since trade matches are proportional to the fraction of buyers. If there is little liquidity, $M_{D} / P<\underline{m}$, sales are infrequent. Thus, sellers prefer to charge high prices, offering the lower quantity $a q_{D}$. As liquidity grows, $\underline{m}<M_{D} / P<\bar{m}$, there are more trade encounters and sellers lower prices to earn some surplus whenever gains from trade exist. At higher liquidity levels, $M_{D} / P>\bar{m}$, sale opportunities are so plentiful that sellers can afford to target high-value customers by offering $a q_{D}$. Figure 1 , area A, provides an illustration. ${ }^{12}$

[Figure 1 approximately here]

\subsection{One International Currency}

We now consider international monetary exchange, by conjecturing an equilibrium in which

\footnotetext{
${ }^{11}$ Existence is proved using a constructive method. Given candidate strategies we find parameter regions where strategies are optimal. Thus, $\bar{\rho}, \underline{m}, \underline{m^{\prime}}, \bar{m}, \bar{\alpha}_{F}$ and $\bar{\alpha}_{D}^{\prime}$ are positive-valued functions of the parameters.

${ }^{12}$ In our benchmark case the domestic economy is three times larger than the foreign: $r=0.1, P=0.75, \gamma=0.8$, $a=0.75, k=10$, and $k^{\prime}=0.25$. In this case $\alpha_{D}=7.5>\alpha_{F}^{\prime}=2.5>\alpha_{D}^{\prime}=0.1875>\alpha_{F}=0.0625$. The space $M_{D} \times M_{F}$ is divided in increments of size $10^{-3}$.
} 
foreigners use only money $F$, while domestic agents use both currencies, i.e. $\pi_{D}=\pi_{F}=\pi_{F}^{\prime}=$ 1 and $\pi_{D}^{\prime}=0$. In this case money $F$ facilitates international trade.

In an equilibrium where the lowest reservation price is selected, $q_{D}$ must once again satisfy (15). In pricing goods in money $F$, however, sellers must take into account the expected national and international demand. Since foreign money can be valued differently across borders, there are four potentially different reservation prices to choose from. A domestic seller of good $i$, for instance, can target domestic buyers of either high or low valuation, i.e. $Q_{F, i}$ may satisfy $u_{i}\left(Q_{F, i}\right)=V_{F}-V_{s}$ or $u_{i-1}\left(Q_{F, i}\right)=V_{F}-V_{s}$, respectively. Alternatively, he can target foreign buyers, of either high or low valuation, i.e. $Q_{F, i}$ may satisfy $u_{i}\left(Q_{F, i}\right)=V_{F}^{\prime}-V_{s}^{\prime}$ or $u_{i-1}\left(Q_{F, i}\right)=V_{F}^{\prime}-V_{s}^{\prime}$, respectively. Foreigners face equivalent choices.

When posting the lowest reservation price is an equilibrium and the law of one price holds:

$$
q_{F}^{\prime}=q_{F} \quad \text { such that }\left(a q_{F}\right)^{\gamma}=\max \left\{V_{F}-V_{s}, V_{F}^{\prime}-V_{s}^{\prime}\right\}
$$

To pin down $q_{F}$ we conjecture (and later verify) that domestic buyers have a lower reservation price than foreigners of the same type, i.e. in equilibrium

$$
V_{F}-V_{s} \geq V_{F}^{\prime}-V_{s}^{\prime}
$$

Hence, everyone targets low-valuation domestic buyers, and the equilibrium quantity satisfies:

$$
\left(a q_{F}\right)^{\gamma}=V_{F}-V_{s}
$$

In this case $\beta_{F, h}\left(q_{F, i}\right)=\beta_{F, h}^{\prime}\left(q_{F, i}\right)=\beta_{D, h}\left(q_{D, i}\right)=1$ for $h \in\{i, i-1\}$, and (2)-(4) imply that if $M_{D}<P$, the stationary distribution of money is:

$$
m_{F}=\frac{M_{F}\left(P-M_{D}\right)}{P\left(1-M_{D}\right)}, \quad m_{D}=\frac{M_{D}}{P}, \quad m^{\prime}=m_{F}^{\prime}=\frac{M_{F}}{1-M_{D}}, \quad m_{D}^{\prime}=0
$$

The key result is that there are more domestic and less foreign buyers than if currencies circulated only locally, as some foreign money is held abroad. It is also easy to verify three facts. The domestic economy has the greatest proportion of buyers, $m>m^{\prime}$, since both monies circulate there. Second, there are more domestic buyers with foreign than domestic money if there is less domestic than foreign money, i.e. $m_{F} \geq m_{D}$ if $M_{F}>M_{D}$. Third, foreigners are more likely to have foreign money than domestic agents, $m_{F}^{\prime}>m_{F}$, as that is the only money used by foreigners. 
Unlike the prior section, unfortunately (5)-(7) cannot be substantially simplified. Finding the equilibrium prices, proving their uniqueness, and verifying that sellers do not want to deviate from the proposed strategies requires a more complicated analysis which delivers two main results. First, under certain sufficient conditions on $a$ and $\rho$, a unique positive vector $\left\{q_{D}, q_{F}\right\}$ exists that satisfies (15) and (19). In particular, $q_{D}=\delta^{\frac{1}{\gamma}} q_{F}$ where $\delta$ is greater than one, and monotonically decreases to one as $\alpha_{F} \rightarrow 0$. Second, when we consider an environment where international markets are not as well integrated as national, $\alpha_{D}>\alpha_{F}$ and $\alpha_{F}^{\prime}>\alpha_{D}^{\prime}$, parameters exist such that $\left\{q_{D}, q_{F}\right\}$ supports the conjectured equilibrium.

Proposition 2. Consider an environment where $\alpha_{D}>\alpha_{F}$ and $\alpha_{F}^{\prime}>\alpha_{D}^{\prime}$. If $\rho<\tilde{\rho}$, $\underline{a}<a<\bar{a}$, $\alpha_{F}<\tilde{\alpha}_{F}, \alpha_{D}^{\prime}<\tilde{\alpha}_{D}^{\prime}$, and $P \geq \underline{P}$ then there exists a unique low-price equilibrium where:

(i) money $F$ circulates internationally and the law of one price holds,

(ii) money D circulates locally and prices are homogeneous,

(iii) $q_{D}=\delta^{\frac{1}{\gamma}} q_{F}$, where $\delta>1$, and domestic agents have the lowest reservation prices. Proof. In Appendix.

Some elements of the proposition reflect our prior findings. For instance, low prices require 'patient' sellers, $\rho<\tilde{\rho}$. Borders must act as a trade barrier, $\alpha_{D}^{\prime}<\tilde{\alpha}_{D}^{\prime}$, to inhibit international circulation of the domestic currency. The restrictions on the parameter $a$ are equivalent to those earlier seen for money stocks, but more convoluted due to greater analytical complexity. In short, equilibrium prices that are low and locally homogenous require a moderate liquidity level.

The remaining elements insure that the law of one price holds. Recall that in the equilibrium constructed buyers of different nationalities have different reservation prices, as they value unequally the same money. Although foreigners are willing to pay more than domestic agents (with same tastes), sellers cannot offer prices based on the buyer's nationality. Thus, two conditions must hold: (i) a domestic seller must have no incentive to target foreign traders, charging a price above the market, while (ii) a foreign seller must rely substantially on international trade, to be motivated to keep prices low. The first requisite calls for difficulties in cross-border commerce, $\alpha_{F}<\tilde{\alpha}_{F}$, while the existence of a large domestic economy complies with both, $P>\underline{P}$ (we note that $\underline{P}>1 / 2$ ).

The intuition is this. All else equal, a bigger domestic economy raises (resp. worsens) the 
international trade opportunities available to foreigners (resp. domestic agents). Thus, foreigners prefer to keep prices as low as abroad, to avoid seeing a relevant part of their demand evaporate. Domestic sellers, too, prefer to target own countrymen, keeping prices low. The gain from raising prices to target foreigners would be too small, due to the limited volume of international sales.

Area B in Figure 1, supports the equilibrium described. Interestingly, it exists when the domestic per-capita money stock is small, but the foreign is relatively plentiful $\left(M_{D}<M_{F}\right.$ where the equilibrium exists, and $P>1 / 2$ ). As money use in our model is the result of decentralized individual decisions, the occurrence of currency substitution may then be interpreted as stemming from the domestic economy's need for liquidity services. Scarcity of money in our model hampers the execution of spot transactions. It may therefore be optimal to integrate into the local economy the foreign currency obtained through international trade, to sustain internal trade. ${ }^{13}$

\subsection{Two international currencies.}

We now prove that equilibria with the law of one price can be supported when the monies compete to sustain international and local trade. To do so, suppose that both monies sustain trade everywhere, i.e. $\boldsymbol{\pi}$ is a unit vector. Hence, there are at most four reservation prices in each currency, that a seller could post. They parallel those seen in the prior section, for sales in currency $F$. When posting the lowest reservation price is an equilibrium and the law of one price holds

$$
q_{d}^{\prime}=q_{d} \quad \text { such that }\left(a q_{d}\right)^{\gamma}=\max \left\{V_{d}-V_{s}, V_{d}^{\prime}-V_{s}^{\prime}\right\} \quad \forall d
$$

As done previously, we pin down traded quantities by conjecturing (and then verifying) that in equilibrium domestic agents have the lowest reservation price, for trades in any currency, i.e. $V_{d}-$ $V_{s} \geq V_{d}^{\prime}-V_{s}^{\prime} \forall d$. The equilibrium quantities must then satisfy:

$$
\left(a q_{d}\right)^{\gamma}=V_{d}-V_{s} \forall d
$$

When every seller posts the lowest reservation price, $\beta_{d, i}\left(q_{d, h}\right)=1 \forall d, i$ and $h=i, i+1$. It is

\footnotetext{
${ }^{13} \mathrm{~A}$ parallel can be drawn with the extensive currency substitution that took place in the Ottoman Empire in the second half of the $17^{\text {th }}$ century (see Pamuk, 1997). Debased European silver coins (among others), spent by European traders, were widely circulating at a premium over their specie content, without any form of government intervention. The reason is that Ottoman markets were in need of money, especially the small denomination. While aware of the link between availability of money and economic prosperity, the Ottoman bureaucracy could not meet this liquidity demand (due to silver shortages, and difficulties with the production of copper coinage).
} 
easily proved that the stationary distribution of money is unique and it satisfies

$$
m_{d}^{\prime}=m_{d}=M_{d} \forall d
$$

hence $m=m^{\prime}=M \cdot{ }^{14}$ This implies that, relative to the monetary regime with local circulation, $m$ and $m^{\prime}$ do not vary if $M_{D} / P=M_{F} /(1-P)$, while if $M_{D} / P<M_{F} /(1-P)$ they are respectively larger and smaller (the opposite, in the complementary case). This is because money stocks that circulate internationally must be divided among a greater number of agents. Thus, if the per-capita national money stocks differ, opening the monies to international circulation increases the liquidity of the country which had the smallest amount, and lowers that available to the other country. The key result is that a 'shift' to a different monetary regime has opposing effects on the liquidity available in different countries.

The great deal of symmetry of the proposed equilibrium has analytical benefits. Expressions (5) and (7) are quite simple:

$$
\begin{aligned}
& \rho V_{s}=2\left(\alpha_{D} m_{D}+\alpha_{F} m_{D}^{\prime}\right)\left(V_{D}-q_{D}-V_{s}\right)+2\left(\alpha_{D} m_{F}+\alpha_{F} m_{F}^{\prime}\right)\left(V_{F}-q_{F}-V_{s}\right) \\
& \rho V_{d}=2\left[\alpha_{D}(1-m)+\alpha_{F}\left(1-m^{\prime}\right)\right]\left(V_{s}-V_{d}+\frac{1+a^{\gamma}}{2} q_{d}^{\gamma}\right)
\end{aligned}
$$

For example, the first line in (23) tells us that sales for currency $d$ occur at rate $2\left(\alpha_{D} m_{d}+\alpha_{F} m_{d}^{\prime}\right)$ since two types of buyers, in each country, spend money at the posted price. The buyer's expected surplus (second line) is $V_{s}-V_{d}+\frac{1+a^{\gamma}}{2} q_{d}^{\gamma}$, as he buys goods that he likes a little or a lot.

Using (21)-(23) it is easy to verify that, in the conjectured equilibrium, $V_{D}=V_{F}$ and $V_{D}^{\prime}=V_{F}^{\prime}$. Therefore, the traded quantities are unique and such that $q_{D}=q_{F}=q$ where:

$$
q=\left\{\frac{a^{\gamma}\left[\rho+\left(\alpha_{D}+\alpha_{F}\right)(1+m)\right]-\left(\alpha_{D}+\alpha_{F}\right)(1-m)}{2 m\left(\alpha_{D}+\alpha_{F}\right)}\right\}^{\frac{1}{1-\gamma}} .
$$

The following summarizes the result on existence of equilibrium.

Proposition 3. Consider an environment where $\alpha_{D}>\alpha_{F}$ and $\alpha_{F}^{\prime}>\alpha_{D}^{\prime}$. If $\rho \leq \overline{\bar{\rho}}, P \geq \underline{\underline{P}}$, $\underline{\underline{m}}<M<\overline{\bar{m}}$, and $\alpha_{F}<\overline{\bar{\alpha}}$ then there exists a unique low-price equilibrium where

\footnotetext{
${ }^{14}$ The distribution is symmetric across economies, as the number of matches among domestic and foreign agents is identical to that among foreign and domestic agents. Since both currencies circulate everywhere, the steady state fractions of buyers must be identical across countries, for any money. Because the world's population is of unit mass, the buyers with money $d$ must equal the population proportion initially endowed with that money, $M_{d}$.
} 
(i) both currencies circulate internationally and the law of one price holds,

(ii) $q_{D}=q_{F}=q$, and domestic agents have the lowest reservation prices.

Proof. In Appendix.

A key feature of this equilibrium is that prices are independent of the money used, so that the currencies are perfect substitutes. This is because the currencies are identically useful media of exchange, as their endogenous liquidity is identical. First, both monies give rise to identical trade prospects, as sellers post prices in either currency everywhere. Second, the monies purchasing power is invariant to sellers' locations, because the law of one price holds in equilibrium. Thus, the two monies must be perfect substitutes, $V_{D}=V_{F}$, and prices must be identical in the two currencies. ${ }^{15}$

While the explanation for most of the restrictions on parameters is as in the monetary regime with only internal trade, two reasons explain the lower bound on $P$. Domestic buyers have the lowest reservation price only if they can trade at least as frequently as foreigners. Since international markets do not function as well as national, the domestic population must then be at least as large as the foreign. Under these circumstances, however, foreign sellers must also want to keep prices as low as the rest of the world. As seen earlier, they are motivated to do so only if a substantial fraction of their demand originates abroad. Technically, $V_{d} \geq V_{d}^{\prime}$ only if $P \geq .5$, as in this case $\alpha_{F}+\alpha_{D} \geq \alpha_{F}^{\prime}+\alpha_{D}^{\prime}($ and $\underline{\underline{P}} \geq .5)$.

Area C in Figure 1, supports the equilibrium described. Predictably, it exists when the combined money stocks are too small to support any other circulation patterns seen before. However, it may also coexist with them, as it is always best for a seller to post prices in every money that is expected to facilitate internal trade. Aggregate liquidity cannot be too large in this case, or the seller would be motivated to raise prices above the market's uniformly low prices. This explains why equilibria do not coexist when either of the money stocks is large.

\subsection{The Terms of Trade and Welfare.}

Having studied existence of the different monetary regimes, we make some observations on the behavior of prices. Before doing so, we point out a noteworthy aspect of our trading environment.

\footnotetext{
${ }^{15}$ This parallels the finding of Wright and Trejos (2001) for the same monetary regime. In their model, however, the monies' purchasing powers differ across countries unless the economies are identical. Furthermore, perfect substitutability is not a general implication of our model. To see why, consider equilibria where trades in a currency occur at different prices across borders.
} 
Corollary. Monetary equilibria do not exist when every seller posts the highest reservation price.

The proof is obvious. No buyer earns surplus if the highest reservation prices are posted everywhere. This implies $V_{d}=0<V_{s} \forall d$ so that money has no value. Thus, monetary equilibria are impossible if buyers are homogeneous and have no bargaining power. Monetary exchange can be sustained when the price mechanism guarantees sufficient trade surplus to buyers, either because they have bargaining power, or because they are heterogeneous. The average terms of trade, that is, cannot be too unfavorable to buyers. The patterns of monetary exchange we have studied, for example, cannot be sustained if too few buyers have high valuations, $a \rightarrow 0$, or if valuation disparities are minimal, $a \rightarrow 1$. In these cases only the highest reservation price would be posted.

How do prices vary with the underlying economic environment? The equilibria presented share two key properties. First, greater initial money stocks tend to support equilibria with lower prices. Second, better trading environments tend to support equilibria with higher prices. This is easy to see when either both or no money circulates internationally ${ }^{16}$, while the analysis is not as clear cut when there is only one international currency.

These features, although surprising, are easily explained. A greater initial stock of money raises the proportion of buyers, in the model. This makes it harder to buy but easier to sell. Hence money will be valued only if buyers can get higher surplus per trade. Thus, sellers must produce more in equilibrium. The negative link between prices and arrival rates has a different root. A better functioning trading environment boosts trade opportunities, hence raises reservation prices. Buyers can afford to 'spend more' as both buying but also earning money is made easier. Sellers are aware of this, and thus raise prices.

Table 1 reports traded quantities for the equilibria existing in Figure 1, given $M_{D}$ and varying $M_{F}$. If $M_{D}=.1$ equilibria with local or international circulation of monies may coexist. If $M_{D}=0.025$, the monetary regime with only one international currency arises.

[Table 1 approximately here]

\footnotetext{
${ }^{16}$ Consider (17). Then $\frac{\partial q_{D}}{\partial m}>0$ since $\bar{\rho}<\frac{\alpha_{D}\left(1-a^{\gamma}\right)}{a^{\gamma}}$ (similarly, $\left.\frac{\partial q_{F}^{\prime}}{\partial m^{\prime}}>0\right) ; \frac{\partial q_{D}}{\partial \alpha_{D}}<0 ; \frac{\partial q_{F}^{\prime}}{\partial \alpha_{F}^{\prime}}<0$. An identical result holds when we consider (24), as $q$ falls in $\alpha_{D}+\alpha_{F}$ and rises in $m$.
} 
Under international circulation there is a unique worldwide price, $q^{-1}$, that falls as aggregate liquidity grows. Under local circulation, local commodity prices fall in the initial stock of local money. They are independent of prices and money abroad, as international trade is absent. Note also that domestic prices are higher than foreign, because the domestic economy has the greatest size. This implies that internal trade is more difficult abroad than in the domestic economy, $\alpha_{D}>\alpha_{F}^{\prime}$, while per-capita liquidity tends to be scarcer domestically $\left(m_{D}<m_{F}^{\prime}\right.$ for $\left.M_{F} \geq .04\right)$. In the monetary regime with one international currency greater liquidity is also associated with lower prices. However, $q_{D}$ is affected by $M_{F}$, despite that domestic money supports only internal trade. The reason is that different stocks of foreign money imply different trade opportunities for domestic agents. This impinges on the relative valuation of currencies in a way that we discuss below.

\subsubsection{The Relative Price of Currencies}

It is important to recognize that international trade hurdles do not per se impair the domestic acceptability of a foreign money. The key is whether the money is expected to sustain internal trade. Once both monies sustain local trade, however, their relative value is affected by their relative ease of circulation, due to their explicit medium-of-exchange role.

The two monies trade at par when they both circulate internationally. ${ }^{17}$ When money $F$ is the only one sustaining international trade, however, it has purchasing power lower than money $D$. That is, the implied exchange rate (under purchasing power parity) is greater than unity: at the equilibrium market prices, $\delta^{\frac{1}{\gamma}}$ units of money $F$ would trade for money $D .{ }^{18}$

This is perhaps surprising, as money $F$ can be more easily spent. Recall, however, that traded quantities reflect the reservation price of low-valuation domestic agents. Thus, a domestic seller should not target foreigners (who have higher reservation prices). Incentives to do so exist if equilibrium prices are higher in money $F$. Also, when money $D$ has only domestic use in equilibrium, domestic agents must have an extra incentive to acquire it. A reason to do so exists if prices are

\footnotetext{
${ }^{17}$ This would not generally hold if buyers could trade money and goods amongst them (see Aiyagari et al, 1996).

${ }^{18}$ Such a 'home currency bias' is not a general property of equilibria with an international currency $\left(q_{F}>q_{D}\right.$ is possible when $\left.V_{F}^{\prime}-V_{s}^{\prime}>V_{F}-V_{s}\right)$. We think it is interesting, however, as it proves that an international currency does not necessarily have greater purchasing power than a national, when money's value depends on its liquidity. This contrasts with results obtained by Wright and Trejos (2001), when prices depend solely on the seller's nationality. They find that the international currency generally purchases more at home than abroad (i.e. the law of one price does not hold), and has greater purchasing power abroad than the local currency.
} 
lower in the domestic than in the competing currency. Numerical experiments indicate that the price differential falls as the disparity in trading opportunities falls $\left(q_{D}\right.$ falls and $q_{F}$ rises as $\alpha_{F}$ decreases). As the countries grow isolated domestic revenues increasingly depend on national sales, while foreign money is increasingly used for internal trade. This lessens the currencies' disparity in spending opportunities and in relative values.

\subsubsection{Prices and Welfare across Monetary Regimes}

Because different monetary regimes coexist, it is interesting to evaluate prices across them. The key observation is that extending the use of a currency to a different economy does not generally imply lower prices. This may seem surprising since this increases the currency's liquidity and opens up trade opportunities. However, the trade patterns linked to different monetary regimes affect prices through two distinct and often conflicting effects.

First, given a distribution of money, greater circulation implies larger trade possibilities. As seen earlier, this increases buyers' reservation prices, hence the prices posted. Comparing $q$ to $q_{D}$ from (15), for example, $q<q_{D}$ when $m$ changes marginally (which occurs if the countries have similar trading environments). Greater circulation, however, affects also the distribution of money. Because the proportions of domestic and foreign buyers are affected unequally in general, prices move differently in the two countries. An increase in the fraction of domestic buyers, for example, tends to push domestic prices down, and foreign prices up. ${ }^{19}$ Thus, the analysis suggests that integrating separate monetary systems may not necessarily support lower prices in all countries, and it may support higher prices everywhere.

Table 1 illustrates this. When $M_{D}=.1$ and $M_{F}$ is sufficiently small, domestic and foreign prices are lower when neither money circulates abroad. For greater $M_{F}$, however, a greater amount of liquidity is available domestically when the monies circulate everywhere (indicated using ${ }^{*}$ ) by the corresponding $M_{F}$ values) hence domestic prices are lower than in the competing monetary regime. The effect on foreign prices, however, remains negative. If we reduce the stock of domestic money by $75 \%$, its international circulation always lowers the liquidity domestically available. Thus the regime where both monies circulate internationally sustains higher prices everywhere.

The upshot is that, from a welfare standpoint, increased circulation may be detrimental to

\footnotetext{
${ }^{19}$ Recall that higher $m$ implies lower domestic reservation prices. It lowers worldwide prices, when international trade occurs, as in the equilibria studied every seller targets domestic buyers.
} 
one or both economies, despite its obvious benefits for ease of trade and the ability to consume. Such an instance is seen in Table 1, reporting the average lifetime utility of a domestic agent, $W=(1-m) V_{s}+m_{D} V_{D}+m_{F} V_{F}$, and its foreign equivalent $W^{\prime}$. Welfare is lower everywhere when prices are higher in both economies. It is higher, however, in the country where prices fall (e.g. the domestic economy for $M_{D}=.1$, indicated by $\left.{ }^{(*)}\right)$. Whether worldwide welfare rises or falls, in this case, depends on the relative size of the two countries.

\section{Concluding Remarks.}

We have considered a two-country, two-currency decentralized trading environment in which two monies compete to support spot trade on international markets that are less integrated than national. Prices are endogenously formed via a seller-posting-price protocol, and currency use is the result of uncoordinated individual decision processes. Heterogeneity in the countries' trading environments and the presence of international trade frictions may induce cross-country price disparities that cannot be easily arbitraged away.

The central result is the proof of existence of a class of equilibria where every seller posts identical prices, under different monetary regimes. Thus, our study suggests that the presence of barriers to the international flow of goods does not necessarily imply a tendency for different prices to be paid for the same good, at the same time, in different parts of the international market. Due to its level of abstraction, ours is not meant to be a comprehensive model of international monetary trade. However, the approach adopted provides a useful conceptual framework to study prices in a monetary setting where the integration of markets and the role of money are made explicit.

\section{References}

Aiyagari S. R., N. Wallace and R. Wright (1996) "Coexistence of Money and Interest-Bearing Securities," Journal of Monetary Economics 37, 397-420.

Camera, G. and D. Corbae, (1999) "Money and Price Dispersion," International Economic Review, Vol.40, 4, 985-1008.

Curtis-Soller, E. and R. Wright (2000), "Price Setting and Price Dispersion in a Monetary Economy," manuscript, University of Pennsylvania.

Green E. , and R. Zhou (1998) "A Rudimentary Model of Search with Divisible Money and Prices," Journal of Economic Theory. 
Hellwig M. F. (1993), "The challenge of monetary theory," European Economic Review, 37, 215-242 Kiyotaki, N. and R. Wright (1989), "On Money as a Medium of Exchange," Journal of Political Economy 97, 927-954.

Matsuyama K., N. Kiyotaki and A. Matsui (1993), "Toward a Theory of International Currency," Review of Economic Studies, 60, 283-307.

Pamuk, Ş. (1997), "In the Absence of Domestic Currency: Debased European Coinage in the Seventeenth-Century Ottoman Empire," Journal of Economic History, 57, 345-366

Rauch, J.E. (1999) "Network versus markets in international trade," Journal of International Economics, 48, 7-35

Rogoff K., (1996) "The Purchasing Power Parity Puzzle," Journal of Economic Literature, 34, $647-668$

Wright R., and A. Trejos (2001) "International Currency," Advances in Macroeconomics, Vol.1,No.1, Article 3.

\section{Appendix}

\section{Proof of Proposition 1.}

We discuss domestic traders (the argument is similar for foreigners). Rearranging (16):

$$
V_{D}-V_{s}=\frac{q_{D} \alpha_{D}\left[q_{D}^{\gamma-1}(1-m)+2 m\right]}{\rho+\alpha_{D}(1+m)}
$$

which, jointly with (15), implies (17). If $m>\underline{m} \equiv \frac{\alpha_{D}\left(1-a^{\gamma}\right)-\rho a^{\gamma}}{\alpha_{D}\left(1+a^{\gamma}\right)} \in(0,1)$, then $q_{D}>0$ (resp. $\left.m^{\prime}>\underline{m}^{\prime} \equiv \frac{\alpha_{F}^{\prime}\left(1-a^{\gamma}\right)-\rho a^{\gamma}}{\alpha_{F}^{\prime}\left(1+a^{\gamma}\right)} \in(0,1) \Rightarrow q_{F}^{\prime}>0\right)$.

1. $\pi_{D}=1$ and the low price is optimal. The seller must have positive surplus, i.e. $q_{D}<\bar{q}$ since $q_{D}<V_{D}-V_{s} \Rightarrow q_{D}<\left(a q_{D}\right)^{\gamma}$. The low price corresponds to $q_{D}$ satisfies (15); the high price corresponds to $a q_{D}$. Charging the low price is optimal if $\Omega\left(q_{D}\right)>\Omega\left(a q_{D}\right)$, i.e. $q_{D}^{1-\gamma} \leq \frac{a^{\gamma}}{2-a}$ (which also assures $q_{D}<\bar{q}$ ) or:

$$
\alpha_{D}\left[m a^{1+\gamma}+(2-a)\left(1-m-a^{\gamma}\right)\right] \geq(2-a) a^{\gamma} \rho
$$

The LHS of the inequality is positive if $m<\bar{m} \equiv \frac{(2-a)\left(1-a^{\gamma}\right)}{2-a\left(1+a^{\gamma}\right)} \in(0,1)$. Hence, the inequality holds if $\rho \leq \rho_{D} \equiv \frac{\alpha_{D}\left[m a^{1+\gamma}+(2-a)\left(1-m-a^{\gamma}\right)\right]}{(2-a) a^{\gamma}}$ and $m<\bar{m}$. Note that $0<\underline{m}<\bar{m}<1, \underline{m}$ and $\bar{m}$ 
fall in $a$, and $\bar{m} \rightarrow \gamma /(2+\gamma)$ as $a \rightarrow 1$ (by L'Hospital rule). Thus there are $M_{D}$ that satisfy $m=\frac{M_{D}}{P} \in(\underline{m}, \bar{m}) \forall a, P$. Additionally, $\lim _{a \rightarrow 1} \rho_{D}=0$ and $\left(0, \rho_{D}\right)$ is non-empty $\forall a, m$. One can similarly show that $\pi_{F}^{\prime}=1$ is individually optimal and $q_{F}^{\prime}$ in (17) maximizes $\Omega^{\prime}\left(q_{F}^{\prime}\right)$ if $m^{\prime}<\bar{m}$ and $\rho \leq \rho_{F} \equiv \frac{\alpha_{F}^{\prime}\left[m^{\prime} a^{1+\gamma}+(2-a)\left(1-m^{\prime}-a^{\gamma}\right)\right]}{(2-a) a^{\gamma}}$. Hence, if $\rho \leq \bar{\rho} \equiv \min \left\{\rho_{D}, \rho_{F}\right\}, m>\underline{m}$, $m^{\prime}>\underline{m^{\prime}}$, and $m, m^{\prime}<\bar{m}$ then $\pi_{D}=\pi_{F}^{\prime}=1$ and $\left\{q_{D}, q_{F}^{\prime}\right\}$ are individually optimal.

2. $\pi_{F}=0$. The necessary condition is that no surplus can be earned from selling to a foreign buyer (there are no domestic buyers with currency $F$, since $m_{F}=0$ in equilibrium), even if when lowest reservation quantity, i.e. when $V_{F}-V_{s} \leq a q_{F}^{\prime}$. Here $q_{F}^{\prime}=\frac{\left(V_{F}^{\prime}-V_{s}^{\prime}\right)^{1 / \gamma}}{a}$ is the quantity offered by foreign sellers to low-valuation foreigners (i.e. the low price).

Suppose, then, that a domestic agent has sold for currency $F$, out of equilibrium. Now he can only buy abroad. Hence:

$$
\rho V_{F, i}=\alpha_{F}\left(1-m_{F}^{\prime}\right) \sum_{h \in \mathbf{N}} \max _{B_{F, i}\left(q_{F, h}^{\prime}\right)} B_{F, i}\left(q_{F, h}^{\prime}\right)\left[V_{s, i}+u_{i}\left(q_{F, h}^{\prime}\right)-V_{F, i}\right]
$$

where $B_{F, i}\left(q_{F, h}^{\prime}\right)$ defines an action that is unspecified, along the equilibrium path (no domestic agents have currency $F$, in equilibrium). However we know that if $V_{F}-V_{s} \leq a q_{F}^{\prime}$ (as it must be if $\pi_{F}=0$ ) then $V_{F}-V_{s}<\left(a q_{F}^{\prime}\right)^{\gamma}$ (this is because $\left(a q_{F}^{\prime}\right)^{\gamma}>a q_{F}^{\prime}$, given that $a q_{F}^{\prime}<1$ ) so that $B_{F, i}\left(q_{F, h}^{\prime}\right)=1$ for $h=i, i+1$.

Using (15), (16), and (25):

$$
\left(V_{F}-V_{s}\right)\left[\rho+2 \alpha_{F}\left(1-m_{F}^{\prime}\right)\right]=\alpha_{F}\left(1-m_{F}^{\prime}\right)\left(q_{F}^{\prime}\right)^{\gamma}\left(1+a^{\gamma}\right)-2 \alpha_{D} m_{D}\left[\left(a q_{D}\right)^{\gamma}-q_{D}\right] .
$$

The inequality $V_{F}-V_{s} \leq a q_{F}^{\prime}$, thus can be then rearranged as

$$
\alpha_{F} \leq \bar{\alpha}_{F} \equiv \frac{2 \alpha_{D} m\left[\left(a q_{D}\right)^{\gamma}-q_{D}\right]+\rho a q_{F}^{\prime}}{\left(1-m^{\prime}\right)\left(q_{F}^{\prime}\right)^{\gamma}\left[1+a^{\gamma}-2 a^{\gamma}\left(q_{F}^{\prime}\right)^{1-\gamma}\right]}
$$

where $q_{D}$ and $q_{F}^{\prime}$ satisfy (17). The RHS is independent of $\alpha_{F}$; also, $\bar{\alpha}_{F}>0$ because $1+$ $a^{\gamma}-2 a^{\gamma}\left(q_{F}^{\prime}\right)^{1-\gamma}>0$ (its smallest value, achieved at $q_{F}^{\prime}=1$, is positive). Thus $\alpha_{F}<\bar{\alpha}_{F}$ is sufficient for $\pi_{F}=0$ to be individually optimal. Similar reasoning is used to prove that if

$$
\alpha_{D}^{\prime}<\bar{\alpha}_{D}^{\prime} \equiv \frac{2 \alpha_{F}^{\prime} m^{\prime}\left[\left(a q_{F}^{\prime}\right)^{\gamma}-q_{F}^{\prime}\right]+\rho a q_{D}}{(1-m) q_{D}^{\gamma}\left[1+a^{\gamma}-2 a^{\gamma} q_{D}^{1-\gamma}\right]} .
$$

then $\pi_{D}^{\prime}=0$ is optimal. Clearly, there are $k^{\prime}$ that satisfy $\alpha_{F} \leq \bar{\alpha}_{F}$ and $\alpha_{D}^{\prime}<\bar{\alpha}_{D}^{\prime}$ jointly. 


\section{Existence of Equilibria with One International Currency}

This is only a sketch of a more detailed proof contained in Camera and Winkler (2002).

Using (5)-(7) and (19), in equilibrium

$$
\begin{gathered}
\left(V_{D}-V_{s}\right) b_{1}=b_{2} q_{D}^{\gamma}+b_{3} q_{D}-b_{4}\left(V_{F}-q_{F}-V_{s}\right) \\
\left(V_{F}-V_{s}\right) c_{1}=c_{2} q_{F}^{\gamma}+b_{4} q_{F}-b_{3}\left(V_{D}-q_{D}-V_{s}\right) \\
\left(V_{F}^{\prime}-V_{s}^{\prime}\right) d_{1}=d_{2} q_{F}^{\gamma}+d_{3} q_{F},
\end{gathered}
$$

where the following are positive values:

$$
\begin{gathered}
b_{1}=\rho+\alpha_{D}\left(1+m_{D}-m_{F}\right), b_{2}=\alpha_{D}(1-m), b_{3}=2 \alpha_{D} m_{D}, b_{4}=2\left(\alpha_{D} m_{F}+\alpha_{F} m_{F}^{\prime}\right) \\
c_{1}=\rho+\alpha_{D}\left(1-m_{D}+m_{F}\right)+\alpha_{F}\left(1+m_{F}^{\prime}\right), c_{2}=\alpha_{D}(1-m)+\alpha_{F}\left(1-m_{F}^{\prime}\right) \\
d_{1}=\rho+2 \alpha_{D}^{\prime}\left(1-m_{D}\right)+2 \alpha_{F}^{\prime}, d_{2}=\left[\alpha_{D}^{\prime}(1-m)+\alpha_{F}^{\prime}\left(1-m_{F}^{\prime}\right)\right]\left(1+a^{\gamma}\right), d_{3}=2\left(\alpha_{D}^{\prime} m_{F}+\alpha_{F}^{\prime} m_{F}^{\prime}\right)
\end{gathered}
$$

The RHS of (29) is positive for all $q_{F}>0$, but we do not know whether $V_{F}-V_{s} \geq V_{F}^{\prime}-V_{s}^{\prime}$. To find an equilibrium price vector, we proceed in three steps. First, in Lemma 1, we provide conditions such that a unique positive pair $\left\{q_{D}, q_{F}\right\}$ solves the system (27)-(28). Then, using (29), we provide sufficient conditions for (18) to hold (in Lemma 2). Finally, we provide conditions such that $\left\{q_{D}, q_{F}\right\}$ maximizes sellers' profits (Lemma 3).

Using (15) and (19), (27)-(28) can be rewritten as:

$$
\left\{\begin{array}{l}
q_{D}^{\gamma}\left[\frac{a^{\gamma} b_{1}-b_{2}}{b_{3}}\right]+\frac{b_{4}}{b_{3}}\left[\left(a q_{F}\right)^{\gamma}-q_{F}\right]=q_{D} \\
q_{F}^{\gamma}\left[\frac{a^{\gamma} c_{1}-c_{2}}{b_{4}}\right]+\frac{b_{3}}{b_{4}}\left[\left(a q_{D}\right)^{\gamma}-q_{D}\right]=q_{F},
\end{array}\right.
$$

defining a map which has a fixed point $q_{D}=q_{F}=0$ corresponding to the non-monetary equilibrium. Under certain conditions, it also has a unique positive fixed point $\left\{q_{D}, q_{F}\right\}$.

Because we are interested in situations in which international trade is difficult, in building the proofs we will consider the case where $\alpha_{D}>\alpha_{F}$ and $\alpha_{F}^{\prime}>\alpha_{D}^{\prime}$, i.e. $k>k^{\prime}$ and $P>1 / 2$, and $\alpha_{F}$ is small. 
Lemma 1. If $a \in\left(\underline{a}, a_{H}\right), \rho<\tilde{\rho}$, and $\alpha_{F}<\alpha_{1}$ the map defined by (30) has a unique fixed point $\left\{q_{D}, q_{F}\right\} \in(0, \bar{q})^{2}$, where:

$$
q_{F}=\left(\frac{a^{\gamma} c_{1}-c_{2}+a^{\gamma} b_{3} \delta}{b_{4}+b_{3} \delta^{\frac{1}{\gamma}}}\right)^{\frac{1}{1-\gamma}}, q_{D}=q_{F} \delta^{\frac{1}{\gamma}},
$$

with $\tilde{\rho}>0$ and $\delta>1>a_{H}>\underline{a}>0$.

Proof. We provide conditions sufficient for existence and uniqueness of a fixed point $\left(q_{D}, q_{F}\right)$ on a subset of $(0, \bar{q})^{2}$.

1. Finding the fixed point. Let $x_{D}=\left(a q_{D}\right)^{\gamma}-q_{D}$, and $x_{F}=\left(a q_{F}\right)^{\gamma}-q_{F}$. Add and subtract $\left(a q_{D}\right)^{\gamma}$ from the right hand side of the first equation in $(30)$, and $\left(a q_{F}\right)^{\gamma}$ from the second. Rearranging:

$$
\left\{\begin{array}{l}
q_{D}^{\gamma}\left[\frac{a^{\gamma}\left(b_{1}-b_{3}\right)-b_{2}}{b_{3}}\right]+\frac{b_{4}}{b_{3}} x_{F}+x_{D}=0 \\
q_{F}^{\gamma}\left[\frac{a^{\gamma}\left(c_{1}-b_{4}\right)-c_{2}}{b_{4}}\right]+\frac{b_{3}}{b_{4}} x_{D}+x_{F}=0 .
\end{array}\right.
$$

which can be solved to give $q_{D}=q_{F}\left[\frac{a^{\gamma}\left(c_{1}-b_{4}\right)-c_{2}}{a^{\gamma}\left(b_{1}-b_{3}\right)-b_{2}}\right]^{\frac{1}{\gamma}}$. Note that $c_{1}-b_{4}>b_{1}-b_{3}>0$, and that $c_{1}-b_{4} \equiv \rho+c_{2}$ and $b_{1}-b_{3} \equiv \rho+b_{2}$. Thus let $\delta \equiv \frac{a^{\gamma}\left(\rho+c_{2}\right)-c_{2}}{a^{\gamma}\left(\rho+b_{2}\right)-b_{2}}$, and rewrite $q_{D}=q_{F} \delta^{\frac{1}{\gamma}}$. Since $\frac{c_{2}}{\rho+c_{2}}>\frac{b_{2}}{\rho+b_{2}}$, then:

- $\delta>0$ if $a>\left(\frac{c_{2}}{\rho+c_{2}}\right)^{\frac{1}{\gamma}}$ or if $a<\left(\frac{b_{2}}{\rho+b_{2}}\right)^{\frac{1}{\gamma}}$;

- $\delta<1$ if $a>\left(\frac{c_{2}}{\rho+c_{2}}\right)^{\frac{1}{\gamma}}$, because $c_{2}>b_{2}$;

- $\delta>1$ if $a<\left(\frac{b_{2}}{\rho+b_{2}}\right)^{\frac{1}{\gamma}}$, since numerator and denominator are both negative, but the former has greater absolute value.

Using $q_{D}=q_{F} \delta^{\frac{1}{\gamma}}$ in the second equation of the system above yields $q_{F}=\left(\frac{a^{\gamma} c_{1}-c_{2}+a^{\gamma} b_{3} \delta}{b_{4}+b_{3} \delta^{\frac{1}{\gamma}}}\right)^{\frac{1}{1-\gamma}}$, increasing in $a$.

2. Show $\left(q_{D}, q_{F}\right) \in(0, \bar{q})^{2}$.

- $q_{F}<\bar{q}$. This is satisfied if $a^{\gamma} b_{3}\left(\delta-\delta^{\frac{1}{\gamma}}\right)<-\left[a^{\gamma} \rho-c_{2}\left(1-a^{\gamma}\right)\right]$. If $a>\left(\frac{c_{2}}{\rho+c_{2}}\right)^{\frac{1}{\gamma}}$ then $\delta<1$, the LHS is positive, but the RHS is negative. Therefore we need $a<a_{H} \equiv$ $\left(\frac{b_{2}}{\rho+b_{2}}\right)^{\frac{1}{\gamma}}$, in which case $\delta>1$, the LHS is negative while the RHS is positive, so that 
$q_{F}<\bar{q}$ and $q_{F}<q_{D}$. When $a<a_{H}$ then $\partial \delta / \partial \alpha_{F}>0$ and $\lim _{\alpha_{F} \rightarrow 0} \delta=1\left(\alpha_{F} \rightarrow 0\right.$ as either $k^{\prime} \rightarrow 0$ or $P \rightarrow 1$ ). Hence, $\lim _{\alpha_{F} \rightarrow 0} q_{F} \rightarrow q_{D}^{+}$.

- $q_{D}, q_{F}>0$. Since $c_{1}>c_{2}$ and $\delta>1$, then $q_{F}>0$ if $a \geq \underline{a} \equiv\left(\frac{c_{2}}{c_{1}+b_{3}}\right)^{\frac{1}{\gamma}}$. Notice that $\underline{a}<a_{H}$ if $\rho<\tilde{\rho} \equiv \frac{b_{2}\left(b_{4}+b_{3}\right)}{c_{2}-b_{2}}$. Furthermore, it is easy to verify that if $a=\underline{a}$ then $\lim _{\alpha_{F} \rightarrow 0} q_{F}=0\left(\right.$ since $\delta \rightarrow 1$ as $\left.\alpha_{F} \rightarrow 0\right)$.

- $q_{D}<\bar{q}$. Recall that $q_{D}>q_{F}>0$ for $a \geq \underline{a}$, and that $q_{F}<\bar{q}$ for $a<a_{H}$. Notice that $\lim _{\alpha_{F} \rightarrow 0} \underline{a}=\frac{\alpha_{D}(1-m)}{\rho+\alpha_{D}(1+m)}<\lim _{\alpha_{F} \rightarrow 0} a_{H}=\frac{\alpha_{D}(1-m)}{\rho+\alpha_{D}(1-m)}$. Recall also that $\lim _{\alpha_{F} \rightarrow 0} q_{D}=q_{F}$ because $\lim _{\alpha_{F} \rightarrow 0} \delta=1$. By the intermediate value theorem it follows that there exists an $\alpha_{1}>0$ small such that if $\alpha_{F}<\alpha_{1}$ and $a \in\left(\underline{a}, a_{H}\right)$ then $\bar{q}>q_{D}>q_{F}>0$

Now we provide sufficient conditions such that if $\left\{q_{D}, q_{F}\right\}$ satisfies (31), then the proposed $\boldsymbol{\pi}$ is optimal, and $V_{F}-V_{s} \geq V_{F}^{\prime}-V_{s}^{\prime}$.

Lemma 2. Consider an environment where $\alpha_{D}>\alpha_{F}$ and $\alpha_{F}^{\prime}>\alpha_{D}^{\prime}$. Let $\left\{q_{D}, q_{F}\right\}$ be defined by (31). If $\underline{a}<a<a_{H 1}, \rho<\tilde{\rho}, P \geq \frac{1+M_{D}}{2}$ and $\alpha_{F}<\alpha_{F 1}$ then: (i) the conditions listed in Lemma 1 hold, (ii) $\pi_{D}=\pi_{F}=\pi_{F}^{\prime}=1$ satisfy (11), and (iii) $V_{F}-V_{s} \geq V_{F}^{\prime}-V_{s}^{\prime}$.

Proof. Let $\left\{q_{D}, q_{F}\right\}$ be as in (31) and let the conditions in Lemma 1 hold.

1. $\pi_{D}=\pi_{F}=1$. Since $\left(a q_{d}\right)^{\gamma}=V_{d}-V_{s}$, then $\Pi_{d}=1$ if $q_{d}<\bar{q}$. This is satisfied by Lemma 1 .

2. $\pi_{F}^{\prime}=1$. Note that $q_{F}<\bar{q}$ is not sufficient to guarantee $\Pi_{F}^{\prime}=1$ because we have conjectured $V_{F}-V_{s} \geq V_{F}^{\prime}-V_{s}^{\prime}$ (we provide conditions for this to hold below). Therefore, we must show that $V_{F}^{\prime}-V_{s}^{\prime}>q_{F} \Rightarrow q_{F}^{1-\gamma}<\frac{d_{2}}{d_{1}-d_{3}}$, whose RHS is positive and increasing in $a$. Recall that $q_{F}$ increases in $a$, if $a=\underline{a}$ then $\lim _{\alpha_{F} \rightarrow 0} q_{F}=0$, and $\lim _{a \rightarrow a_{H}^{-}} q_{F}=\bar{q}$. It follows that there is an $a_{1}>\underline{a}$ and $\alpha_{2}>0$ such that $\underline{a}<a<\min \left\{a_{1}, a_{H}\right\}$ and $\alpha_{F}<\min \left\{\alpha_{1}, \alpha_{2}\right\}$ satisfy $q_{F}^{1-\gamma}<\frac{d_{2}}{d_{1}-d_{3}}$.

3. $V_{F}-V_{s} \geq V_{F}^{\prime}-V_{s}^{\prime}$ holds if $\left(a q_{F}\right)^{\gamma} \geq V_{F}^{\prime}-V_{s}^{\prime}$ i.e.

$$
q_{F}^{1-\gamma} \leq \frac{a^{\gamma} d_{1}-d_{2}}{d_{3}}
$$

The RHS of $(32)$ is positive if $a>a_{2} \equiv\left[\frac{\alpha_{D}^{\prime}(1-m)+\alpha_{F}^{\prime}\left(1-m_{F}^{\prime}\right)}{\rho+\alpha_{D}^{\prime}\left(1-m_{D}+m_{F}\right)+\alpha_{F}^{\prime}\left(1+m_{F}^{\prime}\right)}\right]^{\frac{1}{\gamma}} ; a_{2} \leq \underline{a}$ if $\rho(k-$ $\left.k^{\prime}\right)\left[(1-P)\left(1-m_{F}^{\prime}\right)-(1-m) P\right] \leq 0$. Since $1-m_{F}^{\prime}=\frac{1-M_{D}-M_{F}}{1-M_{D}}$ and $1-m=\frac{P-M_{D}}{P}(1-$ 
$\left.m_{F}^{\prime}\right)$, then $(1-P)\left(1-m_{F}^{\prime}\right) \leq(1-m) P$ whenever $k \geq k^{\prime}$ and $P \geq \frac{1+M_{D}}{2}$. Thus, let $k \geq k^{\prime}$, $P \geq \frac{1+M_{D}}{2}$, and $a>\underline{a}$ so that the RHS of (32) is positive. Since $q_{F}$ increases in $a$, and $\lim _{\alpha_{F} \rightarrow 0} q_{F}=0$ when $a=\underline{a}$, it follows that there exists an $a_{3}>\underline{a}$ and $\alpha_{3}>0$ such that $\underline{a}<a<\min \left\{a_{1}, a_{3}, a_{H}\right\}$ and $\alpha_{F}<\min \left\{\alpha_{1}, \alpha_{2}, \alpha_{3}\right\}$ satisfy (32).

Let $a_{H 1} \equiv \min \left\{a_{1}, a_{3}, a_{H}\right\}$ and $\alpha_{F 1} \equiv \min \left\{\alpha_{1}, \alpha_{2}, \alpha_{3}\right\}$. Notice that (i) $\alpha_{D}>\alpha_{F}$ and $\alpha_{F}^{\prime}>\alpha_{D}^{\prime}$ imply $k>k^{\prime}$, (ii) $\frac{1+M_{D}}{2}>\frac{1}{2}$, and (iii) $\left(\underline{a}, a_{H 1}\right) \subset(0,1)$ and $\left(0, \alpha_{F 1}\right)$ are non-empty sets. Given $\alpha_{D}>\alpha_{F}, \alpha_{F}^{\prime}>\alpha_{D}^{\prime}$, and $\left\{q_{D}, q_{F}\right\}$ as in (31), let $\underline{a}<a<a_{H 1}, \rho<\tilde{\rho}, P \geq \frac{1+M_{D}}{2}$ and $\alpha_{F}<\alpha_{F 1}$. Then, the conditions in Lemma 1 hold, $\pi_{D}=\pi_{F}=\pi_{F}^{\prime}=1$ are individually optimal, and $V_{F}-V_{s} \geq$ $V_{F}^{\prime}-V_{s}^{\prime}$ as conjectured.

Finally, we provide sufficient conditions such that if (i) $\left\{q_{D}, q_{F}\right\}$ satisfies (31), (ii) the proposed vector $\boldsymbol{\pi}$ is individually optimal, and (iii) $V_{F}-V_{s} \geq V_{F}^{\prime}-V_{s}^{\prime}$, then $\left\{q_{D}, q_{F}\right\}$ and $\pi_{D}^{\prime}=0$ are also individually optimal.

Lemma 3. Consider an environment where $\alpha_{D}>\alpha_{F}$ and $\alpha_{F}^{\prime}>\alpha_{D}^{\prime}$. Let $\left\{q_{D}, q_{F}\right\}$ be defined by (31). If $\underline{a}<a<\bar{a}, \rho<\tilde{\rho}, \alpha_{F}<\tilde{\alpha}_{F}, \alpha_{D}^{\prime}<\tilde{\alpha}_{D}^{\prime}$, and $P>\underline{P}$, then: (i) the conditions listed in Lemma 2 hold, (ii) $\pi_{D}^{\prime}=0$ satisfies (11) and (iii) $\left\{q_{D}, q_{F}\right\}$ satisfy (10).

Proof. To show that profits are maximized when $\left\{q_{D}, q_{F}\right\}$ satisfies (31), consider $\Omega\left(Q_{d}\right)$ and $\Omega^{\prime}\left(Q_{d}^{\prime}\right)$ under all possible one-time deviations in offers. ${ }^{20}$ Let the conditions in Lemma 2 hold.

1. $q_{D}$ is optimal. The only deviation, $\tilde{Q}_{D}=a q_{D}$, is suboptimal if

$$
\Omega\left(q_{D}\right)=\frac{2 \alpha_{D} m_{D}}{N}\left(V_{D}-q_{D}-V_{s}\right)>\Omega\left(a q_{D}\right)=\frac{\alpha_{D} m_{D}}{N}\left(V_{D}-a q_{D}-V_{s}\right) .
$$

which amounts to $q_{D}^{1-\gamma}<\frac{a^{\gamma}}{2-a}$. Recall that $q_{D} \rightarrow 0$ as $q_{F} \rightarrow 0$, and that $\lim _{\alpha_{F} \rightarrow 0} q_{F}=0$ for $a=\underline{a}$, where $q_{F}$ increases in $a$. Hence, there exists an $a_{4}>\underline{a}$ and $\alpha_{4}>0$ such that $\underline{a}<a<\min \left\{a_{4}, a_{H 1}\right\}$ and $\alpha_{F}<\min \left\{\alpha_{4}, \alpha_{F 1}\right\}$ satisfy $q_{D}^{1-\gamma}<\frac{a^{\gamma}}{2-a}$.

2. $\pi_{D}^{\prime}=0$. We need to show $\Omega^{\prime}\left(Q_{D}^{\prime}\right) \leq 0 \forall Q_{D}^{\prime} \geq a q_{D}$, i.e. the quantity bought by a high valuation domestic buyer with $D$ ( $\operatorname{since} \pi_{D}^{\prime}=m_{D}^{\prime}=0$ no foreign buyers are expected). Thus,

\footnotetext{
${ }^{20}$ Notice that although a domestic seller chooses both $Q_{D}$ and $Q_{F}$, we cannot consider simultaneous deviations, since the matched buyer carries only one currency.
} 
$\pi_{D}^{\prime}=0$ if $V_{D}^{\prime}-a q_{D}-V_{s}^{\prime} \leq 0$. Out of equilibrium

$$
\rho V_{D, i}^{\prime}=\alpha_{D}^{\prime}(1-m) \sum_{h \in \mathbf{N}} \max _{B_{D, i}^{\prime}\left(q_{D, h}\right)} B_{D, i}^{\prime}\left(q_{D, h}\right)\left[V_{s, i}^{\prime}+u_{i}\left(q_{D, h}\right)-V_{D, i}^{\prime}\right]
$$

No matter what the $B_{D, i}^{\prime}\left(q_{D, h}\right)$ are, $V_{D, i}^{\prime} \rightarrow 0$ as $\alpha_{D}^{\prime} \rightarrow 0$, but $q_{D}$ and $V_{s}^{\prime}$ remain positive. Since $\lim _{k^{\prime} \rightarrow 0} \alpha_{D}^{\prime}=0$, it follows by continuity that there exists a $k^{\prime}$ small enough that satisfies $\pi_{D}^{\prime}=0$. For a given $P$ let this value of $k^{\prime}$ define the positive quantity $\tilde{\alpha}_{D}^{\prime}$. Hence choose $\alpha_{D}^{\prime}<\tilde{\alpha}_{D}^{\prime}$

3. $q_{F}$ is optimal for a domestic seller. In equilibrium $\Omega\left(q_{F}\right)=\frac{2}{N}\left(\alpha_{D} m_{F}+\alpha_{F} m_{F}^{\prime}\right)\left(V_{F}-q_{F}-\right.$ $\left.V_{s}\right)$. Suppose a domestic seller deviates by offering the quantity $\tilde{Q}_{F}<q_{F}$. At this lower quantity one or both types of foreigners might buy, but only the high valuation domestic agents buy. Consider the case where $\alpha_{F} \rightarrow 0$, when revenues from foreign sales vanish. Since $\lim _{\alpha_{F} \rightarrow 0} \Omega\left(\tilde{Q}_{F}\right)=\frac{\alpha_{D} m_{F}}{N}\left(V_{F}-\tilde{Q}_{F}-V_{s}\right)$ the relevant deviation is to offer the low reservation quantity, $\tilde{Q}_{F}=a q_{F}$. Hence, as $\alpha_{F} \rightarrow 0$ then $\Omega\left(q_{F}\right)>\Omega\left(a q_{F}\right) \Rightarrow q_{F}^{1-\gamma}<\frac{a^{\gamma}}{2-a}$. We have seen that $q_{D}^{1-\gamma}<\frac{a^{\gamma}}{2-a}$ if $\underline{a}<a<\min \left\{a_{4}, a_{H 1}\right\}$ and $\alpha_{F}<\min \left\{\alpha_{4}, \alpha_{F 1}\right\}$. Since $q_{F}<q_{D}$, then there is an $\alpha_{5}>0$ such that $q_{F}^{1-\gamma}<q_{D}^{1-\gamma}<\frac{a^{\gamma}}{2-a}$ if $\underline{a}<a<\min \left\{a_{4}, a_{H 1}\right\}$ and $\alpha_{F}<\min \left\{\alpha_{4}, \alpha_{5}, \alpha_{F 1}\right\}$.

4. $q_{F}$ is optimal for a foreign seller. Since $\Omega^{\prime}\left(q_{F}\right)=\frac{2}{N}\left(\alpha_{F}^{\prime} m_{F}^{\prime}+\alpha_{D}^{\prime} m_{F}\right)\left(V_{F}^{\prime}-q_{F}-V_{s}^{\prime}\right)$ and $\alpha_{F}^{\prime}>\alpha_{D}^{\prime}$, foreign sellers might choose to offer less than $a q_{F}$ because $V_{F}^{\prime}-V_{s}^{\prime} \leq V_{F}-V_{s}$ (i.e. foreign buyers earn some surplus since $V_{s}^{\prime}-V_{F}^{\prime} \geq V_{s}-V_{F}$ ). However we know that as $P \rightarrow 1$ then $\alpha_{F}^{\prime} \rightarrow 0$ and $\Omega^{\prime}\left(q_{F}\right) \rightarrow \frac{2}{N} \alpha_{D}^{\prime} m_{F}\left(V_{F}^{\prime}-q_{F}-V_{s}^{\prime}\right)$ in which case the relevant price deviation is $\tilde{Q}_{F}=a q_{F}$. It is easy to verify that as $P \rightarrow 1$ then $\Omega^{\prime}\left(q_{F}\right)>\Omega^{\prime}\left(\tilde{Q}_{F}\right) \Rightarrow(2-a) d_{1}-d_{3}<$ $d_{2} q_{F}^{\gamma-1}$. This holds as $a \rightarrow \underline{a}$ and $\alpha_{F} \rightarrow 0$ since in that case $q_{F} \rightarrow 0$ while $(2-a) d_{1}-d_{3}$ does not. By continuity there is a $P_{1}<1, a_{5}>\underline{a}$ and $\alpha_{6}>0$ such that $q_{F}$ is optimal for foreign sellers, if $P>P_{1}, \underline{a}<a<\min \left\{a_{4}, a_{5}, a_{H 1}\right\}$ and $\alpha_{F}<\min \left\{\alpha_{4}, \alpha_{5}, \alpha_{6}, \alpha_{F 1}\right\}$.

Let $\bar{a} \equiv \min \left\{a_{4}, a_{5}, a_{H 1}\right\}, \tilde{\alpha}_{F} \equiv \min \left\{\alpha_{4}, \alpha_{5}, \alpha_{6}, \alpha_{F 1}\right\}$ and $\underline{P}>\max \left\{P_{1}, \frac{1+M_{d}}{2}\right\}$. Notice that $(\underline{a}, \bar{a}) \subset(0,1),\left(0, \tilde{\alpha}_{F}\right),\left(0, \tilde{\alpha}_{D}^{\prime}\right)$ and $(\underline{P}, 1) \subset(0,1)$ are non-empty sets. Finally, given $\alpha_{D}>\alpha_{F}$, $\alpha_{F}^{\prime}>\alpha_{D}^{\prime}$, and $\left\{q_{D}, q_{F}\right\}$ as in (31), let $\underline{a}<a<\bar{a}, \rho<\tilde{\rho}, \alpha_{F}<\tilde{\alpha}_{F}, \alpha_{D}<\tilde{\alpha}_{D}^{\prime}$, and $P>\underline{P}$. Thus: (i) the conditions listed in Lemma 2 hold, (ii) $\pi_{D}^{\prime}=0$ satisfies (11) and (iii) $\left\{q_{D}, q_{F}\right\}$ satisfy (10). 
Proof of Proposition 2. Choose $k>k^{\prime}$ and $P \geq \underline{P}$ such that $\alpha_{D}>\alpha_{F}$ and $\alpha_{F}^{\prime}>\alpha_{D}^{\prime}$. Let $\underline{a}<a<\bar{a}, \rho<\tilde{\rho}, \alpha_{F}<\tilde{\alpha}_{F}$, and $\alpha_{D}<\tilde{\alpha}_{D}^{\prime}$. Then this supports the existence of the equilibrium where money $F$ circulates internationally, money $D$ circulates domestically, sellers post the lowest reservation prices, the law of one price holds, and $V_{F}-V_{s} \geq V_{F}^{\prime}-V_{s}^{\prime}$.

\section{Proof of Proposition 3.}

This proof is similar to that of Proposition 1. Consider a domestic agent. Using (22)-(23) and defining $h_{0}=\rho+\left(1+m_{D}-m_{F}\right)\left(\alpha_{D}+\alpha_{F}\right), h_{1}=(1-m)\left(\alpha_{D}+\alpha_{F}\right), h_{2}=2\left(\alpha_{D}+\alpha_{F}\right), h_{3}=$ $\rho+\left(1+m_{F}-m_{D}\right)\left(\alpha_{D}+\alpha_{F}\right)$, then

$$
\begin{aligned}
& \left(a q_{D}\right)^{\gamma} h_{0}=h_{1} q_{D}^{\gamma}+h_{2}\left(m_{D} q_{D}+m_{F} q_{F}\right)-h_{2} m_{F}\left(a q_{F}\right)^{\gamma} \\
& \left(a q_{F}\right)^{\gamma} h_{3}=h_{1} q_{F}^{\gamma}+h_{2}\left(m_{D} q_{D}+m_{F} q_{F}\right)-h_{2} m_{D}\left(a q_{D}\right)^{\gamma} .
\end{aligned}
$$

Subtract the second from the first line:

$$
a^{\gamma}\left[\rho+\left(\alpha_{D}+\alpha_{F}\right)(1-m)\right]\left(q_{D}^{\gamma}-q_{F}^{\gamma}\right)=\left(\alpha_{D}+\alpha_{F}\right)(1-m)\left(q_{D}^{\gamma}-q_{F}^{\gamma}\right)
$$

There is a non monetary equilibrium, $q_{d}=0 \forall d$. As long as $a^{\gamma}\left[\rho+\left(\alpha_{D}+\alpha_{F}\right)(1-m)\right] \neq\left(\alpha_{D}+\right.$ $\left.\alpha_{F}\right)(1-m)$ then there is a unique monetary equilibrium $q_{D}=q_{F}=q$, with $q$ as in (24). If $a^{\gamma}\left[\rho+\left(\alpha_{D}+\alpha_{F}\right)(1-m)\right]=\left(\alpha_{D}+\alpha_{F}\right)(1-m)$ then $q=\bar{q}$, hence $a^{\gamma}\left[\rho+\left(\alpha_{D}+\alpha_{F}\right)(1-m)\right] \neq$ $\left(\alpha_{D}+\alpha_{F}\right)(1-m)$ whenever $q<\bar{q}$. If $m=M>\underline{\underline{m}} \equiv \frac{\left(\alpha_{D}+\alpha_{F}\right)\left(1-a^{\gamma}\right)-\rho a^{\gamma}}{\left(\alpha_{D}+\alpha_{F}\right)\left(1+a^{\gamma}\right)} \in(0,1)$ then $q>0$.

If $q_{F}=q_{D}=q$ then $V_{D}^{\prime}=V_{F}^{\prime}=V^{\prime}$ and $V_{D}=V_{F}=V$, and

$$
\begin{gathered}
V^{\prime}-V_{s}^{\prime}=\frac{\left(\alpha_{D}^{\prime}+\alpha_{F}^{\prime}\right)\left[(1-m)\left(1+a^{\gamma}\right) q^{\gamma}+2 m q\right]}{\rho+2\left(\alpha_{D}^{\prime}+\alpha_{F}^{\prime}\right)} \\
V-V_{s}=\frac{\left(\alpha_{D}+\alpha_{F}\right)\left[(1-m)\left(1+a^{\gamma}\right) q^{\gamma}+2 m q\right]}{\rho+2\left(\alpha_{D}+\alpha_{F}\right)}
\end{gathered}
$$

Thus, $V-V_{s} \geq V^{\prime}-V_{s}^{\prime}$ if $\alpha_{D}+\alpha_{F} \geq \alpha_{D}^{\prime}+\alpha_{F}^{\prime}$, which is satisfied if $P \geq 1 / 2$ and $k>k^{\prime}$ (i.e. it is consistent with $\alpha_{D}>\alpha_{F}$ and $\left.\alpha_{F}^{\prime}>\alpha_{D}^{\prime}\right)$. If $P=1 / 2$ then $V-V_{s}=V^{\prime}-V_{s}^{\prime} \forall k \geq k^{\prime}$.

Clearly $\pi_{D}=\pi_{F}=1$ if $q<\bar{q}$, i.e. $q^{1-\gamma}<a^{\gamma}$, while $q$ maximizes $\Omega\left(q_{d}\right)$ if $\Omega(q)>\Omega\left(\tilde{q}_{d}\right)$ for any $\tilde{q}_{d}<q=\left(V-V_{s}\right)^{\frac{1}{\gamma}} / a$ that is acceptable to some buyer, where $\Omega(q)=\frac{2}{N}\left(\alpha_{D}+\alpha_{F}\right) M_{d}\left(V-q-V_{s}\right)$. Following the proof of Lemma $3, \lim _{\alpha_{F} \rightarrow 0} \Omega(q)=\frac{2 \alpha_{D} M_{d}}{N}\left(V-q-V_{s}\right)$. Thus the relevant deviation is to offer the low reservation quantity, $\tilde{q}_{d}=a q$, as $\alpha_{F}$ vanishes. Hence, as $\alpha_{F} \rightarrow 0$ then $\Omega(q)>$ $\Omega(a q) \Rightarrow q^{1-\gamma}<\frac{a^{\gamma}}{2-a}$ (which also implies $q<\bar{q}$ ), an inequality satisfied for $\rho \leq \rho_{D}$ and $m<\bar{m}$. 
Thus, by continuity there is an $\overline{\bar{\alpha}}>0, \rho \leq \rho_{1}$ and $\underline{\underline{m}}<M<\overline{\bar{m}}$ such that $q$ is optimal and $\pi_{D}=\pi_{F}=1$.

The strategy $\pi_{d}^{\prime}=1$ is optimal if $V^{\prime}-V_{s}^{\prime}>q$, amounting to $q^{1-\gamma}<\frac{\left(1+a^{\gamma}\right)(1-m)\left(\alpha_{D}^{\prime}+\alpha_{F}^{\prime}\right)}{\rho+2(1-m)\left(\alpha_{D}^{\prime}+\alpha_{F}^{\prime}\right)}$. To show that $\Omega^{\prime}(q)>\Omega\left(\tilde{q}_{d}\right) \forall \tilde{q}_{d}<q$ (acceptable to some buyer), we follow the proof of Lemma 3: as $P \rightarrow 1$ then $\Omega^{\prime}(q) \rightarrow \frac{2}{N} \alpha_{D}^{\prime} M_{d}\left(V^{\prime}-q-V_{s}^{\prime}\right)$. Thus the only reasonable deviation for a foreign seller is to post the lower quantity $a q$. It follows that $\Omega^{\prime}(q)>\Omega^{\prime}(a q)$ if $q^{1-\gamma} \leq \frac{\alpha_{D}^{\prime}(1-m)\left(1+a^{\gamma}\right)}{\rho(2-a)+2 \alpha_{D}^{\prime}(2-a-m)}$. Note that $\frac{a^{\gamma}}{2-a} \leq \frac{\alpha_{D}^{\prime}(1-m)\left(1+a^{\gamma}\right)}{\rho(2-a)+2 \alpha_{D}^{\prime}(2-a-m)}$ if $\rho \leq \rho_{2} \equiv \frac{\alpha_{D}^{\prime}(1-m)\left[2-a\left(1+a^{\gamma}\right)\right]}{a^{\gamma}}$. Since if $\rho \leq \rho_{1}$ then $q^{1-\gamma}<\frac{a^{\gamma}}{2-a}$, it follows that $q$ is optimal if $P \geq \underline{\underline{P}} \geq 1 / 2$ and $\rho \leq \overline{\bar{\rho}} \equiv \min \left\{\rho_{1}, \rho_{2}\right\}$. Consequently $\pi_{d}^{\prime}=1$ is also optimal, since $2-a>1$. It follows that $\rho \leq \overline{\bar{\rho}}, P \geq \underline{\underline{P}}, \underline{\underline{m}}<M<\overline{\bar{m}}$, and $\alpha_{F}<\overline{\bar{\alpha}}$ support existence of the equilibrium conjectured. 


\begin{tabular}{|c|c|c|c|c|c|c|c|c|}
\hline$M_{D}=.1$ & \multicolumn{5}{|c|}{2 Local } & \multicolumn{3}{|c|}{2 Intern. } \\
\hline$M_{F}$ & $q_{D}$ & $q_{F}^{\prime}$ & $W$ & $W^{\prime}$ & & $q$ & $W$ & $W^{\prime}$ \\
\hline 0 & & & & & & $1.4 \times 10^{-6}$ & .0002 & $7 \times 10^{-5}$ \\
\hline .01 & & & & & & .001 & .049 & .017 \\
\hline .02 & & & & & & .015 & .337 & .119 \\
\hline .03 & .089 & 1.60 & 1.36 & 2.97 & & .061 & 1.02 & .364 \\
\hline $.04^{(*)}$ & .089 & 5.15 & 1.36 & 7.2 & & .158 & $2.17^{(*)}$ & .772 \\
\hline $.05^{(*)}$ & .089 & 9.27 & 1.36 & 10.9 & & .32 & $3.76^{(*)}$ & 1.33 \\
\hline$M_{D}=.025$ & \multicolumn{5}{|c|}{1 Intern. } & \multicolumn{3}{|c|}{2 Intern. } \\
\hline$M_{F}$ & $q_{D}$ & \multicolumn{2}{|c|}{$q_{F}$} & $W$ & $W^{\prime}$ & \multicolumn{3}{|r|}{$W^{\prime}$} \\
\hline .07 & $3.28 \times 10^{-5}$ & \multicolumn{2}{|c|}{$3.24 \times 10^{-5}$} & .002 & .0006 & & & \\
\hline .08 & $3.06 \times 10^{-3}$ & \multicolumn{2}{|c|}{$3.03 \times 10^{-3}$} & .094 & .025 & .0001 & .008 & .003 \\
\hline .09 & .0233 & \multicolumn{2}{|c|}{.023} & .473 & .130 & .005 & .150 & .053 \\
\hline .1 & .081 & \multicolumn{2}{|c|}{.08} & 1.26 & .360 & .033 & .625 & .222 \\
\hline .11 & .194 & \multicolumn{2}{|c|}{.191} & 2.51 & .731 & .103 & 1.54 & .548 \\
\hline .12 & .372 & \multicolumn{2}{|c|}{.367} & 4.19 & 1.24 & .231 & 2.91 & 1.03 \\
\hline .13 & .618 & \multicolumn{2}{|c|}{.61} & 6.22 & 1.87 & .426 & 4.70 & 1.67 \\
\hline .14 & .932 & \multicolumn{2}{|c|}{.92} & 8.53 & 2.61 & & & \\
\hline .15 & 1.30 & \multicolumn{2}{|c|}{1.29} & 11 & 3.43 & & & \\
\hline .16 & 1.74 & \multicolumn{2}{|c|}{1.72} & 13.7 & 4.31 & & & \\
\hline
\end{tabular}

Table 1 - Traded quantities and $W$ are multiplied by $10^{2}$ 


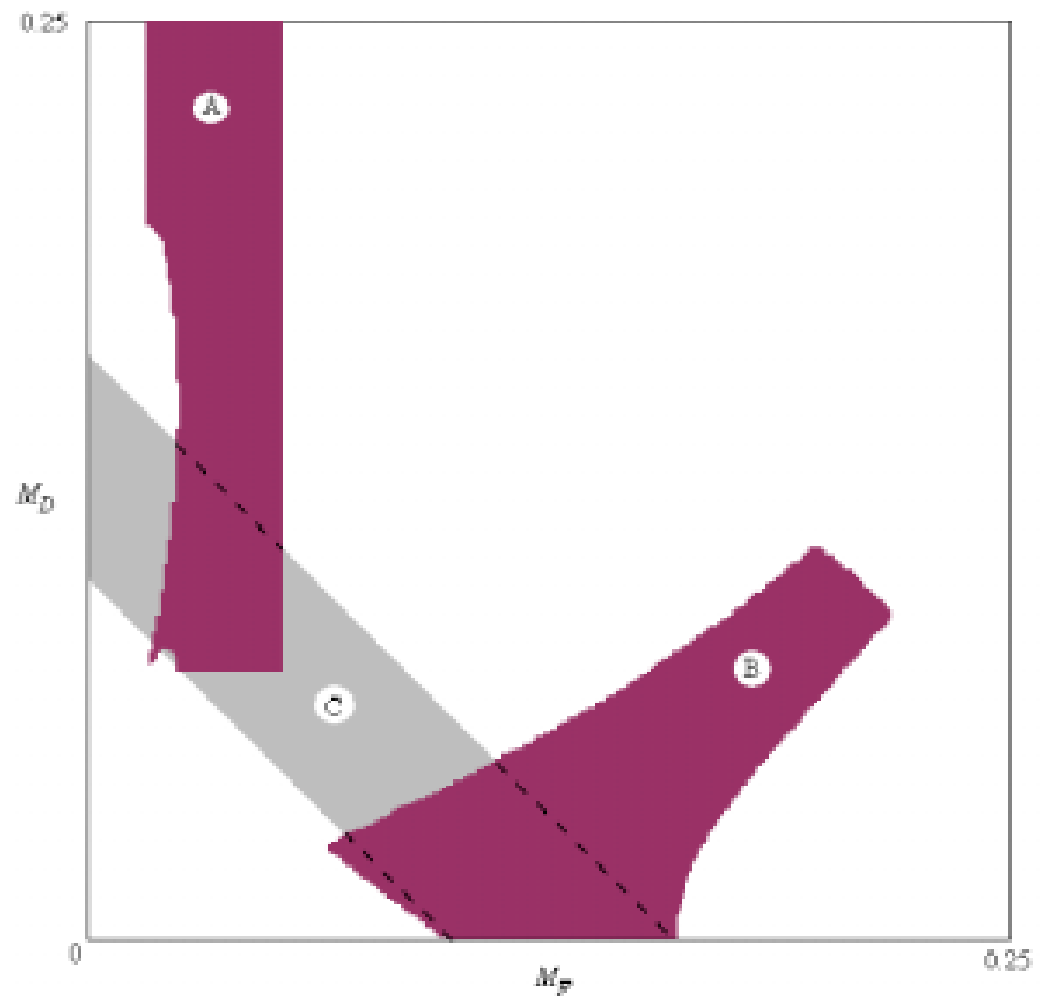

Figure 1 